FERNANDA MENEZES DE OLIVEIRA E SILVA

Morfologia e ultra-estrutura dos órgãos linfoides de cetáceos (Ordem Cetacea, Subordem Odontoceti)

São Paulo 
FERNANDA MENEZES DE OLIVEIRA E SILVA

Morfologia e ultra-estrutura dos órgãos linfoides de cetáceos

(Ordem Cetacea, Subordem Odontoceti)

Tese apresentada ao Programa de PósGraduação em Anatomia dos Animais Domésticos e Silvestres da Faculdade de Medicina Veterinária e Zootecnia da Universidade de São Paulo para obtenção do título de Doutor em Ciências

Departamento:

Cirurgia

Área de Concentração:

Anatomia dos Animais Domésticos e Silvestres

Orientador:

Prof ${ }^{a}$. Dr ${ }^{\mathrm{a}}$. Maria Angélica Miglino

São Paulo

2014 
Autorizo a reprodução parcial ou total desta obra, para fins acadêmicos, desde que citada a fonte.

\section{DADOS INTERNACIONAIS DE CATALOGAÇÃO-NA-PUBLICAÇÃO}

(Biblioteca Virginie Buff D’Ápice da Faculdade de Medicina Veterinária e Zootecnia da Universidade de São Paulo)

Silva, Fernanda Menezes de Oliveira e

Morfologia e ultra-estrutura dos órgãos linfoides de cetáceos (Ordem Cetacea, Subordem Odontoceti) / Fernanda Menezes de Oliveira e Silva. -- 2014.

$62 \mathrm{f}$. : il.

Tese (Doutorado) - Universidade de São Paulo. Faculdade de Medicina Veterinária e Zootecnia. Departamento de Cirurgia, São Paulo, 2014.

Programa de Pós-Graduação: Anatomia dos Animais Domésticos e Silvestres.

Área de concentração: Anatomia dos Animais Domésticos e Silvestres.

Orientador: Prof. ${ }^{\mathrm{a}} \mathrm{Dr}^{\mathrm{a}}$. Maria Angélica Miglino.

1. Cetáceos. 2. Morfologia. 3. Sistema imune. 4. Sistema linfoide. I. Título. 


\section{FOLHA DE AVALIAÇÃO}

Autor: SILVA, Fernanda Menezes de Oliveira e

Título: Morfologia e ultra-estrutura dos órgãos linfoides de cetáceos (Ordem Cetacea, Subordem Odontoceti)

Tese apresentada ao Programa de PósGraduação em Anatomia dos Animais Domésticos e Silvestres da Faculdade de Medicina Veterinária e Zootecnia da Universidade de São Paulo para obtenção do título de Doutor em Ciências

Data:

1

\section{Banca Examinadora}

Prof. Dr.:

Instituição: Julgamento:

Prof. Dr.:

Instituição: Julgamento:

Prof. Dr.:

Instituição: Julgamento:

Prof. Dr.:

Instituição: Julgamento:

Prof. Dr.:

Instituição: Julgamento: 


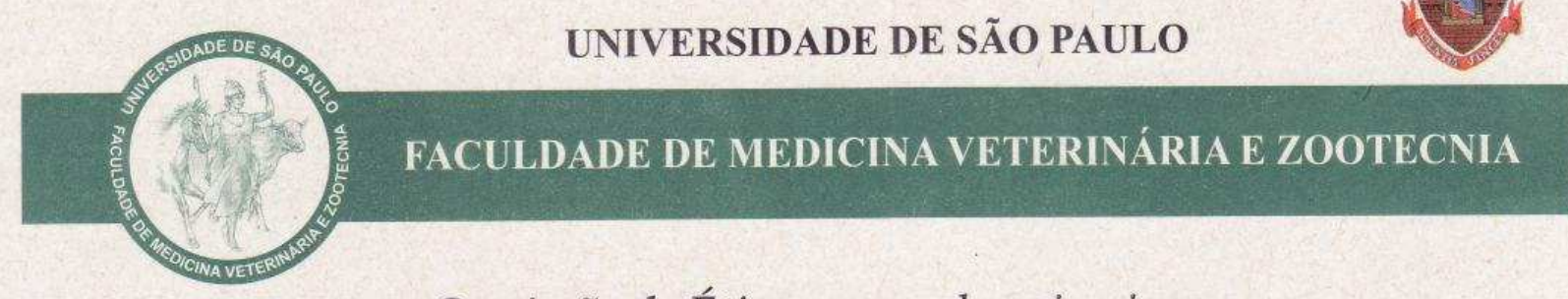

Comissão de Ética no uso de animais

\section{CERTIFICADO}

Certificamos que o Projeto intitulado "Morfologia e ultra-estrutura dos órgãos linfóides de cetáceos (Ordem Cetacea, Subordem Odontoceti)", protocolado sob o $n^{\circ} 2571 / 2012$, utilizando órgãos linfóides de botos e golfinhos, sob a responsabilidade da Profa. Dra. Maria Angélica Miglino, está de acordo com os princípios éticos de experimentação animal da "Comissão de Ética no uso de animais" da Faculdade de Medicina Veterinária e Zootecnia da Universidade de São Paulo e foi aprovado em reunião de 11/4/2012.

We certify that the Research "Morphology and ultrastructure of lymphoid organs of cetaceans (Order Cetacea, Suborder Odontoceti)", protocol number 2571/2012, utilizing lymphoid organs of botos and dolphins, under the responsibility Profa. Dra. Maria Angélica Miglino, agree with Ethical Principles in Animal Research adopted by "Ethic Committee in the use of animals" of the School of Veterinary Medicine and Animal Science of University of São Paulo and was approved in the meeting of day 4/11/2012.

São Paulo, 19 de fevereiro de 2013.

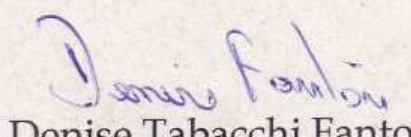

Denise Tabacchi Fantoni

Presidente 
Dedico esse trabalho à minha familia, em especial aos meus pais Manoel e Marlucia, minha avó Harley e meus tios Cleber e Tânia, por todo amor, carinho, paciência, e apoio incondicionais. Agradeço imensamente por estarem sempre ao meu lado durante esses últimos anos de trabalho, que me afastaram de sua convivência, mas nunca de seus corações. Nunca serei capaz de expressar o quanto significam pra mim e o quanto minha vida seria incompleta sem vocês.

Ao meu Marcelo, que, mais que um marido, é companheiro, parceiro, confidente, cúmplice, amigo. Obrigada por fazer minha vida mais repleta e completa de cumplicidade, amor, respeito, carinho, admiração, confiança, determinação e união e por ter entrado de cabeça nessa jornada comigo, sem sequer pestanejar.

Ao longo desses nove anos juntos, sou abençoada em ter você ao meu lado, sempre disposto a embarcar nas minhas aventuras, mesmo que elas significassem sacrifício, renúncia e decisões difíceis. Na falta de palavra melhor no dicionário, te amo.

A Jociery E. Vergara-Parente, que sempre foi meu exemplo de ser humano e profissional. Que mais uma vez me estendeu a mão e abraçou com unhas e dentes este projeto... Seu apoio e confiança tornaram possivel colher cada fruto dele. Não há palavra capaz de descrever o quanto você é espelho que quero ter ao longo da vida.

Á Juliana Plácido Guimarães, que foi meu porto seguro, meu ponto de apoio e de confiança, sem o qual eu não teria sobrevivido a esse doutorado. Obrigada por estar sempre presente, mesmo que ausente, por me dar apoio sem eu nem precisar pedir, me dar bronca quando eu mais precisava e por me ensinar que 0 silêncio é, sempre, melhor que mil palavras. 


\section{AGRADECIMENTOS}

Ao Programa de Pós-graduação em Anatomia dos Animais Domésticos e Silvestres do Departamento de Cirurgia da faculdade de Medicina Veterinária e Zootecnia da Universidade de São Paulo, por todo o suporte físico e técnico para minha formação.

A Profa Maria Angelica Miglino, minha orientadora, pela oportunidade, paciência e confiança, contribuindo para meu crescimento pessoal e profissional, me tornando uma pessoa e profissional mais completas.

Aos Profs. Antonio Assis, Paula Papa e José Roberto Kfoury pelos ensinamentos.

Aos funcionários da Faculdade de Medicina Veterinária e Zootecnia Jaqueline Santana, Edinaldo Ribas, Augusto Eulálio, Maicon Barbosa, Ronaldo Agostinho e Rose Eli Graci, pelas horas de conversa durante o café e por toda a ajuda e apoio que possibilitaram a concretização deste trabalho.

À Fundação de Amparo a Pesquisa do Estado de São Paulo (FAPESP), pelo apoio financeiro em forma de bolsa de doutorado (Processo 2012/01964-0), fundamental para realização deste estudo.

Às instituições Parceiras que colaboraram neste projeto de Pesquisa, que abraçaram a ideia e cederam todas as amostras biológicas utilizadas neste estudo: Fundação Mamíferos Aquáticos - FMA, Associação de Pesquisa e Preservação de Ecossistemas Aquáticos - AQUASIS, Instituto Biota de Conservação e Instituto de Desenvolvimento Sustentável Mamirauá. Obrigada 
por permitirem que eu faça um pouco parte de cada uma destas instituições, que se tornaram um pouco minha família ao longo do processo. Muito obrigada por todo o apoio e confiança em meu trabalho e por não medirem esforços em suas equipes para torná-lo o mais primoroso possível.

Aos parceiros ao longo de anos de trabalho, que vem semeando ideias e colhendo frutos ao meu lado, desde a época de graduação: Vitor Luz, Ana Carolina Meirelles, João Carlos Borges e Bruno Stefanis. Obrigada por confiarem mais uma vez no meu trabalho e estarem sempre com as portas e janelas pras minhas ideias mirabolantes.

À Miriam Marmontel, por estar sempre disposta a ler os trabalhos, sendo a primeira a responder todos os e-mails, mesmo em meio aos inúmeros compromissos de trabalho. Sem sua imensa contribuição científica durante a redação e publicação dos resultados os frutos deste trabalho não seriam os mesmos. Quero ser assim quando eu crescer!

Aos amigos e colegas de pós-graduação, em especial André Luis Franciolli, Erika Toledo, Dayane Alcantara, Marcio Rodrigues, Paula Fratini, Rafael Cardoso, Valdir Pavanello, Nathia Rigoglio, João Leonardo Mendonça, por toda amizade e companheirismo, que fizeram toda diferença ao longo destes três anos. Por ser minha luz no fim do túnel, que muitas vezes parecia interminável... a voz da razão nos momentos de raiva....o ombro amigo no momento de desespero.... o ouvido, mesmo cansado, no momento de necessidade... a mão estendida pra ajudar a pular as pedras no caminho. Sem vocês nada disso seria possível.

A todos que de alguma forma contribuíram para conclusão deste trabalho. Meu muito obrigada, de todo coração! 


\section{RESUMO}

SILVA, F. M. O. Morfologia e ultra-estrutura dos órgãos linfoides de cetáceos (Ordem Cetacea, Subordem Odontoceti). [Morphology and ultrastructure of lymphoid organs in Cetaceans (Order Cetacea, Suborder Odontoceti)]. 2014. 62 f. Tese (Doutorado em Ciências) - Faculdade de Medicina Veterinária e Zootecnia, Universidade de São Paulo, São Paulo, 2014.

Os linfócitos, principais células do sistema imune, podem ser encontrados em órgãos e tecidos de dois grandes sistemas do corpo: o sistema linfático, composto por uma extensa rede de vasos linfáticos e linfonodos; e o sistema linfoide, mais abrangente e que, além de englobar o sistema linfático, abrange todas as células, tecidos e órgãos do corpo que contêm agregados linfocitários, tais como o timo, baço e linfonodos. Embora esteja amplamente descrito para animais domésticos e alguns animais silvestres, estudos sobre o sistema imune em cetáceos são escassos. A influência negativa de contaminantes no sistema imune em mamíferos aquáticos está em constante discussão. Assim, um conhecimento mais profundo da anatomia deste sistema é essencial para a interpretação clínica e de achados de necropsia, para uma melhor compreensão dos achados patológicos. Portanto, o objetivo deste estudo foi caracterizar morfológica e ultraestruturalmente os órgãos do sistema linfoides de odontocetos de ocorrência no litoral brasileiro. As amostras utilizadas foram procedentes de animais encalhados nas regiões norte e nordeste do Brasil. Os órgãos analisados foram baço, timo e linfonodo, bem como os tecidos linfoides associados à mucosa. Primeiramente as amostras foram localizadas topograficamente e avaliadas macroscopicamente. Posteriormente, as amostras foram fixadas e analisadas por microscopias de luz, eletrônica de varredura e transmissão, imunohistoquímica e histomorfometria. Através das análises realizadas foi possível observar que os órgãos e tecidos linfoides em cetáceos são semelhantes ao observado em mamíferos domésticos, com algumas particularidades. Não existem diferenças morfológicas com relação ao timo entre as espécies estudadas, com exceção da não existência de tecido adiposo substituindo o órgão em animais mais jovens, e a presença de Corpúsculos de Hassal mais evidentes em tamanho neste grupo. Novos grupos de linfonodos foram descritos de acordo com a sua localização, entretanto todos possuiram arquitetura semelhante ao descrito na 
literatura para mamíferos terrestres. Os linfonodos estavam dispostos de forma solitária ou em grupos e apresentavam formato variado, recobertos por uma cápsula, e o parênquima do órgão dividiu-se em região cortical e medular. Os centros germinativos apresentaram-se mais evidentes e desenvolvidos em animais filhotes e jovens. Os baços e baços acessórios eram morfologicamente semelhantes, caracterizados por numerosos nódulos linfáticos delimitados pela bainha linfoide periarterial e uma rede celular difusa que circundava os nódulos linfáticos, sem diferenciação entre as camadas cortical e medular. Centros germinativos se tornaram mais discretos e reduzidos em número com o aumento da idade. Os baços acessórios estavam firmemente aderidos ao baço e/ou à grande curvatura da primeira cavidade do estômago, sendo mais prevalentes em animais com maior escore corporal e de mergulhos mais profundos, sugerindo uma função de reservatório sanguíneo complementar. Os tecidos linfoides associados à mucosa em cetáceos foram semelhantes aos observados em mamíferos terrestres, com adaptações inerentes ao meio aquático, como a presença de tonsilas orofaríngea e anal, assegurando uma resposta imunológica mais eficiente diante de desafios antigênicos constantes presentes em seu habitat. Sugere-se que este segmento do sistema linfoide é essencial para a proteção do animal diante dos contaminantes presentes em seu habitat. Com base nos achados do presente estudo, será possível uma melhor compreensão do funcionamento e estrutura do sistema imunológico das espécies estudadas, colaborando na elucidação das causas de encalhe destes animais, que poderão funcionar como potenciais indicadores ambientais.

Palavras-chave: Cetáceos. Morfologia. Sistema imune. Sistema linfoide. 
ABSTRACT

SILVA, F. M. O. Morphology and ultrastructure of lymphoid organs in Cetaceans (Order Cetacea, Suborder Odontoceti). [Morfologia e ultra-estrutura dos órgãos linfoides de cetáceos (Ordem Cetacea, Subordem Odontoceti)]. 2014. 62 f. Tese (Doutorado em Ciências) - Faculdade de Medicina Veterinária e Zootecnia, Universidade de São Paulo, São Paulo, 2014.

Lymphocytes, key cells of the immune system, can be found in organs and tissues of two major systems of the body: the lymphatic system, composed of an extensive network of lymph vessels and lymph nodes; and the lymphoid system, more comprehensive that, in addition to comprise the lymphatic system, includes all cells, tissues and organs containing lymphoid aggregates, such as the thymus and spleen. Although these systems are widely described in domestic animals and some wildlife species, studies about marine mammals are scarce. The negative influence of contaminants in the immune system of aquatic mammals is in constant discussion. The knowledge on the anatomy of these systems is essential for clinical interpretation and necropsy, providing a better understanding of the pathological findings. Therefore, the aim of this study was to characterize the morphology and ultrastructure of lymphoid system of odontocetes occurring in the Brazilian coast. Samples from animals stranded in the northern and northeastern regions of Brazil were collected and organs spleen, thymus and lymph node and mucosa-associated lymphoid tissue were analyzed. First, all samples were evaluated macroscopically and topographically located. Subsequently, they were fixed and analyzed by light microscopy, scanning electron and transmission, immunohistochemistry and histomorphometry. Through these analyzes it was observed that the organs and lymphoid tissues in cetaceans are similar to that observed in domestic mammals, with some peculiarities inherent to their habitat. There were no morphological differences from the thymus in the species studied, except for the absence of adipose tissue replacing the organ in younger animals, and the presence of Hassall corpuscles more prominent in this group. New groups of lymph nodes were described, possessing architecture similar to that described in the literature for terrestrial mammals. Lymph nodes were arranged solitarily or in groups and had 
varied format, covered by a capsule and the parenchyma of the organ was divided into cortical and medullary region. Their germinal centers had become more evident and developed in puppies and young animals. Spleens and accessory spleens were morphologically similar, characterized by numerous lymph nodules delimited by periarterial lymphoid sheath and a diffuse cellular network in its surrounding area, without differentiation between cortical and medullary layers. Germinal centers became more discrete and reduced in number with increasing age. Accessory spleens were firmly adhered to the spleen and / or the greater curvature of the first stomach and were more prevalent in animals with higher body score and dives deeper, suggesting a role of complement blood reservoir. The mucosa-associated lymphoid tissues in cetaceans were similar to those observed in terrestrial mammals, with inherent aquatic adaptations, such as the presence of oropharyngeal and anal tonsils, ensuring a more efficient immune response in the face of constant antigenic challenges present in their habitat. It is suggested that this segment of the lymphoid system is essential for the protection of the animal before the contaminants in their habitat. Based on these findings, this study will enable a better understanding of the structure and functioning of the immune system of the species studied, collaborating in the elucidation of causes of stranding of these animals, whicih may act as potential environmental indicators.

Keywords: Cetaceans. Morphology. Immune system. Lymphoid system. 


\section{LISTA DE FIGURAS}

Figura 1 - Tonsila orofaríngea de Odontocetos

36

Figura 2 - Fotomicrografia de tecidos linfoides associados à mucosa 38

Figura 3 - Intestinos e tecidos linfoides associados à mucosa gastrointestinal em Odontocetos. 39

Figura 4- Intestino e tecido linfoide associado à mucosa gastrointestinal em Inia geofrensis.

Figura 5 - Intestino grosso e tecidos linfoides associados à mucosa gastrointestinal em Odontocetos. 42

Figura 6 - Tonsila anal em Sotalia guianensis 44 


\section{LISTA DE TABELA}

Tabela 1 - Lista de amostras coletadas por espécie, de acordo com o sexo e grupo etário (jovem:filhote:adulto). 


\section{LISTA DE ABREVIATURAS}

AQUASIS

AT

BALT

BIOTA

$\mathrm{CH}$

CODES

FMA

D-MALT

GALT

HE

IDSM

$\mathrm{M}$

MALT

MEV

MET

NK

O-MALT

SALT

TM

$\mu \mathrm{m}$

ᄁm
Associação de Pesquisa e Preservação de Ecossistemas Aquáticos

Azul de Toluidina

Tecido linfoide associado ao sistema respiratório

Instituo Biota de Conservação

Corpúsculo de Hassal

Código para avaliação de carcaça

Fundação Mamíferos Aquáticos

Tecido linfoide associado à mucosa desorganizado

Tecido linfoide associado ao trato gastrointestinal

Hematoxilina-Eosina

Instituto de Desenvolvimento Sustentável Mamirauá

mol

Tecido linfoide associado à mucosa

Microscopia eletrônica de varredura

Microscopia eletrônica de transmissão

Natural Killer

Tecido linfoide associado à mucosa organizado

Tecido linfoide associado à pele

Tricrômio de Masson

Micrômetro

Nanômetro 


\section{SUMÁRIO}

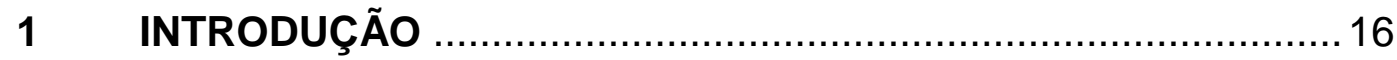

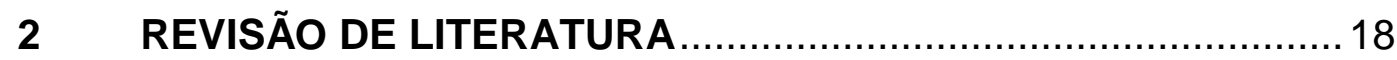

2.1 O SISTEMA IMUNE EM MAMÍFEROS ….................................... 18

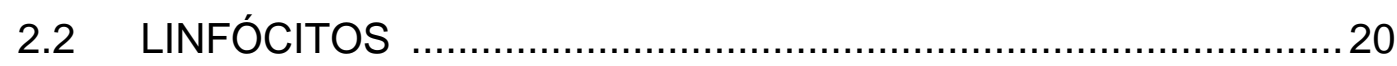

2.3 SISTEMA LINFÁTICO x SISTEMA LINFOIDE ............................22

2.4 SISTEMA E ÓRGÃOS LINFOIDES EM MAMÍFEROS ...................23

2.5 SISTEMA LINFOIDE EM MAMIFEROS AQUÁTICOS....................24

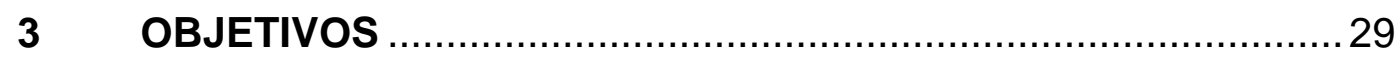

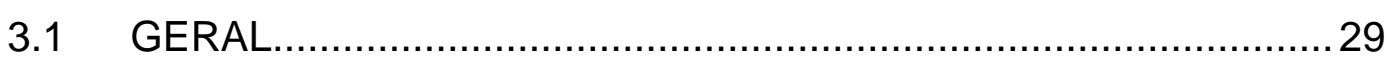

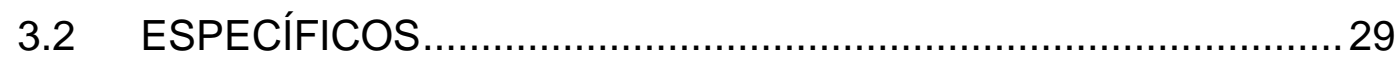

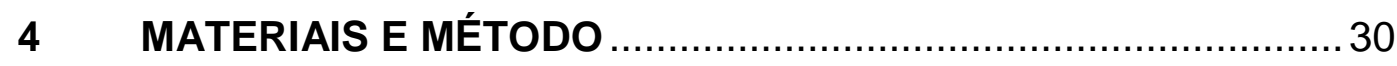

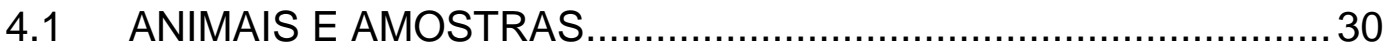

4.2 NECROPSIA E ANÁLISE MACROSCÓPICA ...............................31

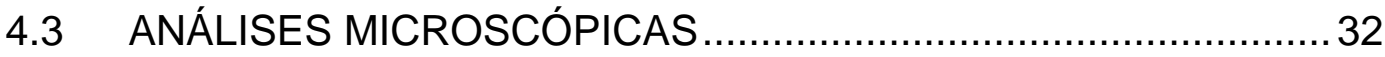

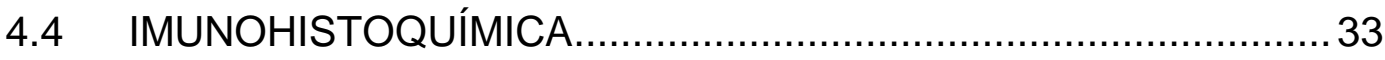

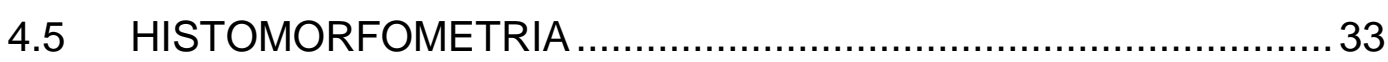

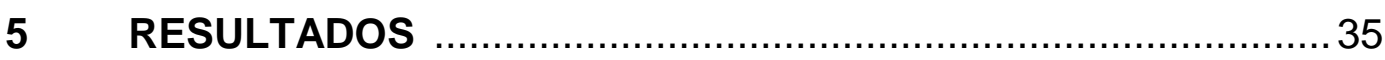

5.1 MORFOLOGIA DOS LINFONODOS, BAÇO E

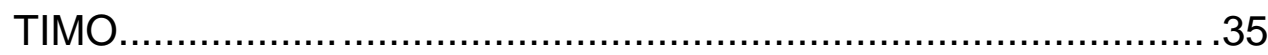

5.2 MORFOLOGIA DOS TECIDOS LINFOIDES ASSOCIADOS À

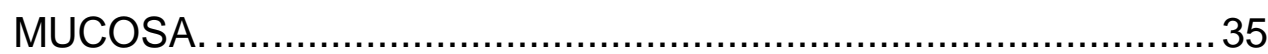

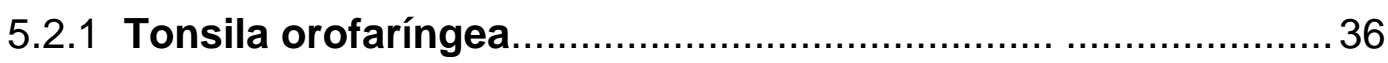

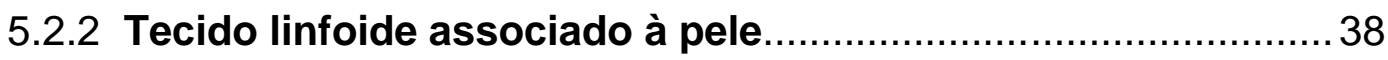

5.2.3 Tecido linfoide associado ao sistema genital feminino ............. 38

5.2.4 Tecido linfoide associado aos vasos sanguíneos...................... 38

5.2.5 Tecido linfoide associado ao trato gastrointestinal .................. 40

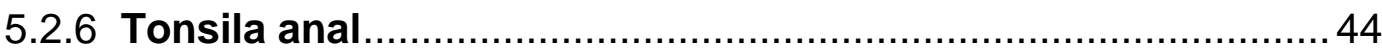

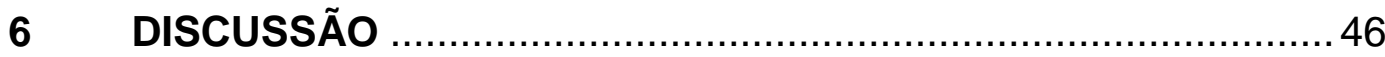

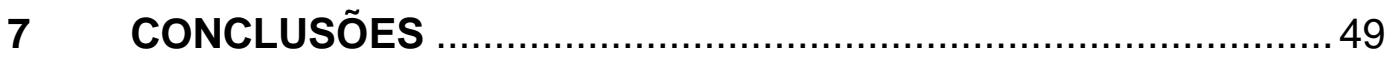

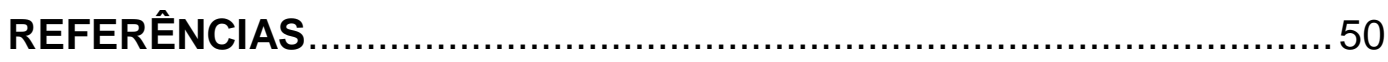

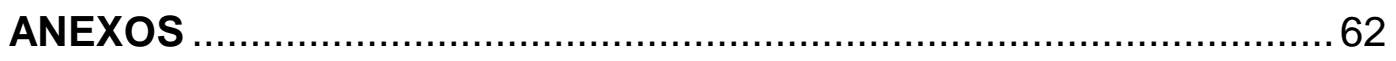




\section{INTRODUÇÃO}

O estudo do sistema hematopoiético envolve os elementos funcionais do sangue, as células progenitoras, os tecidos hematopoiéticos que se encontram na cavidade medular de ossos longos e chatos e em órgãos como baço, fígado, linfonodos e timo (GASPER, 2000). Intimamente ligado a este se encontra o sistema linfático, composto por uma complexa rede de órgãos, ductos, vasos, capilares e tecidos linfoides (DYCE; SACK; WENSING, 2010).

As características fisiológicas e estruturais dos órgãos que compõe estes sistemas são amplamente conhecidas em animais domésticos, como cães e gatos (SISSON; GROSSMAN, 1981; BANKS, 1998; KONIG; LIEBICH, 2011), tendo sua arquitetura e estruturas microscópicas bem definidas. O mesmo também é verificado em diversas espécies de mamíferos selvagens, aves, répteis e anfíbios (CUBAS; SILVA; CATÃO-DIAS, 2007; BABAYAN et al., 2011).

Estudos de anatomia do sistema linfoide de mamíferos aquáticos vêm sendo realizados com ênfase nas características imunológicas para inúmeras espécies. A literatura sobre o desenvolvimento e estrutura deste sistema é escassa e fragmentada (COWAN; SMITH, 1999) para as espécies de mamíferos aquáticos de ocorrência no Brasil, não descrevendo detalhadamente a morfologia dos órgãos constituintes deste sistema.

Para grande parte dos cetáceos, os relatos na literatura são antigos. Simpson e Gardner (1972) obtiveram dados histológicos de determinadas espécies de cetáceos - Odontocetos e Misticetos - e pinípedes. Green (1972) e Harrison (1974) iniciaram os estudos anatômico-funcionais em diferentes espécies de cetáceos e pinípedes, relatados posteriormente por Pabst, Rommel e McLellan (1999). Os estudos sobre a morfologia dos órgãos linfoides (ROMANO et al., 1993; COWAN; SMITH, 1995; COWAN; SMITH, 1999; ROMANO et al., 2002; VUKOVIC et al., 2005) e o funcionamento do sistema imune (BOSSART et al., 2001; ROMMEL; LOWENSTINE, 2001; BEINEKE et al., 2010), muitas vezes limitam-se a uma determinada espécieApesar dos esforços para obtenção de maiores informações acerca do sistema imunológico de pequenos e grandes cetáceos, muito ainda permanece desconhecido (BEINEKE et al., 2010). 
Inúmeras populações de mamíferos aquáticos são influenciadas por fatores antropogênicos, tais como embarcações, poluição sonora, atividades de sísmica (PARENTE, 2008) e poluição por contaminantes (metais pesados e organoclorados). Assim, estudos avaliando a resposta celular e humoral frente à exposição de cetáceos á contaminantes vem sendo realizados (JEPSON et al., 1999), verificando que animais habitando águas menos poluídas por dejetos humanos apresentam menores taxas de infecção bacteriana e parasitismo (SIEBERT et al., 1999).

Embora a causa exata destas doenças permaneça indeterminada, a influência negativa dos contaminantes no sistema imune está em constante discussão. Para uma melhor compreensão dos achados patológicos e fisiológicos atribuídos à ação humana, o conhecimento da anatomia deste sistema é essencial para a interpretação clínica e de achados de necropsia (BEINEKE et al., 2010).

Os órgãos linfoides primários (medula óssea e timo) e secundários (baço e linfonodos) em cetáceos exibem grandes similaridades com os de outras espécies de mamíferos, com algumas particularidades (ROMANO et al., 1993). O baço é de tamanho extremamente diminuto, cerca de $0,02 \%$ do peso corporal do animal, podendo ainda apresentar os chamados 'baços acessórios' (MARCONDES, 2005; CARVALHO et al., 2009). Em Tursiops truncatus, espécie, o timo involui tipicamente após a puberdade como em outras espécies de mamíferos, podendo ainda tornar-se uma formação cística benigna (COWAN, 1994).

O Brasil possui aproximadamente $7500 \mathrm{~km}$ de costa, território no qual 39 espécies de cetáceos já foram notificadas (PINEDO; ROSAS; MARMONTEL, 1992; IBAMA, 2001). Apesar do crescente número de encalhes de animais pertencentes à ordem Cetacea na costa brasileira ao longo dos últimos anos, as pesquisas com mamíferos aquáticos são consideradas recentes, tendo sido iniciada no final da década de 70 (RUOPPOLO, 2005). Apesar dos esforços conservacionistas para a criação de leis e áreas de proteção da fauna marinha brasileira, a grande parte dos animais listados no Plano de Ação para Mamíferos Aquáticos do Brasil (IBAMA, 2001) é classificada na categoria D.D. (Data Deficient - "Dados Insuficientes"; IUCN, 2014).

Diante da necessidade de uma melhor e maior compreensão sobre as características macro e microscópicas dos componentes do sistema imunológico em cetáceos, o presente estudo tem por objetivo avaliar a morfologia do sistema linfoide de espécimes de odontocetos encalhados nas regiões norte e nordeste do Brasil. 


\section{REVISÃO DE LITERATURA}

\subsection{O SISTEMA IMUNE EM MAMÍFEROS}

A imunologia é o estudo dos eventos celulares e molecular que ocorrem no organismo diante da presença de micro-organismos ou substâncias estranhas ao corpo. Para formar uma resposta eficiente à presença destas macro e microléculas agressoras, o corpo forma espécies de barreiras, sejam elas físicas (através de tecidos e órgãos) ou químicas (através das células), que constituem em sua totalidade o chamado sistema imune (COOPER, 2010).

O sistema imunológico ou imune é constituído por inúmeros órgãos linfoides, tecidos linfáticos agregados a outros órgãos e células, que funcionam em sincronia para manutenção da integridade corporal (JANEWAY et al., 2006). Através da identificação de organismos patogênicos ou alérgenos, o sistema imune produz uma resposta que seja apropriada para cada tipo de corpo estranho. No entanto, sua função não é apenas de identificar patógenos e combatê-los, mas também garantir que o corpo seja capaz de responder a estes agentes futuramente, produzindo a chamada memória imunológica (PARHAM, 2009).

As defesas mais eficazes são as que impedem a penetração do antígeno. Sem essa primeira defesa, conhecida como barreira física, fica impossível estabelecer uma proteção adequada. Exemplos clássicos desta barreira e suas respectivas respostas de defesa são a pele e a formação de cicatriz; o trato respiratório e a produção de muco, tosse e espirro; o trato gastrointestinal, com vômitos e diarreia; e o sistema urinário, com a produção de urina em fluxo constante (ABBAS; LICHTMAN; POBER, 2012).

No entanto, a barreira física não é capaz de sozinha impedir que o organismo patogênico cause infecções. Assim como o organismo tem várias formas de se proteger, os patógenos possuem inúmeras formas de infecção e são capazes de se adaptar, rapidamente ou com persistência ao longo do tempo, ao meio em que se encontram, possibilitando sua penetração no hospedeiro (ALAM; GORSKA, 2003). Para que o organismo se preserve, tanto de maneira rápida e imediata como em longo prazo, ele é capaz de produzir mais duas barreiras de defesa: a imunidade 
inata ou natural e a imunidade adquirida ou específica (SHECHTER; LONDON; SCHWARTZ, 2013).

A imunidade inata ou natural é a segunda barreira de defesa e consiste de mecanismos celulares e moleculares de defesa rápida. Uma vez que o microorganismo invasor penetra no organismo, ele é reconhecido como diferente dos componentes normais ali presentes (JANEWAY; MEDZHITOV, 2002). O organismo então centraliza seus mecanismos de defesa inata para o local da infecção, levando a reações teciduais denominadas de inflamação. Durante o processo inflamatório há um aumento do fluxo sanguíneo no local da lesão, permitindo que células se acumulem no local e sejam capazes de atacar o agente invasor e eliminá-lo (JONES; HUNT; KING, 2000).

Cada infecção é tratada de forma independente e característica, não havendo assim imunidade permanente contra o patógeno causador da doença. Apesar de não serem específicas e responder aos patógenos de forma genérica, a resposta inata do sistema de defesa predominante nos mamíferos, esta pronto para responder a qualquer momento em que um invasor for detectado (DELVES et al., 2013).

A inflamação é fundamental para a defesa do organismo, neutralizando a infecção em seu estágio inicial. No entanto, ela é insuficiente uma vez que o sistema de defesa deve ser capaz não só de neutralizar um agente agressor, mas também de memoriza-lo e ser capaz de elaborar uma resposta mais eficiente caso esse agente venha a causar uma nova infecção (MITCHELL et al., 2012). Assim, as imunidades inata e adquirida trabalham em equilíbrio e se complementam em suas ações (IWASAKI; MEDZHITOV, 2010).

A imunidade adquirida consiste na capacidade de reconhecer um invasor, destruí-lo e armazenar a memória relacionada a todo este processo. Para isso, ele requer de um sistema complexo e sofisticado (SMITH-GARVIN; SIGAL, 2013) que envolve duas respostas imunes, a humoral e a celular. A resposta humoral é composta pelos linfócitos $B$, que são capazes de reconhecer antígenos extracelulares e de superfície celular e se diferenciam em células capazes de produzir anticorpos. A resposta celular é composta pelos linfócitos $T$, células de especificidade restrita, que se dividem em Linfócitos T CD4 ou T auxiliares (helpers) e os TCD8 ou T citotóxicos (ABBAS; LICHTMAN; POBER, 2012). 
Além das células $\mathrm{T}$ e $\mathrm{B}$, existem tipos celulares importantes que desempenham papel fundamental nas respostas imunológicas, tais como os macrófagos, as células natural killer (NK, que fagocitam vírus) e as células apresentadoras de antígenos, presentes em todos os tecidos do corpo. Os macrófagos são fundamentais para a resposta imune, inata e adquirida, uma vez que, ao fagocitar os antígenos e processa-los, em seguida, apresenta o antígeno para as células $T$, induzindo sua ativação (TIZARD, 2012).

\subsection{LINFÓCITOS}

No embrião, a hematopoiese inicialmente ocorre no saco vitelino, passando posteriormente para o fígado e baço. No final do desenvolvimento fetal, a hematopoiese passa a ser realizada na medula óssea, onde permanece quase que exclusivamente após o nascimento (HYTTEL, 2012; VEJLSTED, 2012).

Durante o desenvolvimento fetal as células hematopoiéticas na chamada região aorta-gônada-mesonefros colonizam primariamente o fígado, seguindo posteriormente para o timo e baço durante o chamado período hepatoesplênico, e a medula óssea, durante o período medular, dando origem às células das linhagens mieloide e linfoide (LAl; KONDO, 2008; REDECKE et al., 2013).

Recentes pesquisas sugerem que os progenitores linfoides na medula óssea são uma população celular heterogênea, que inicialmente origina a linhagem eritróide/megacariocítica, seguida pela linhagem mieloide, que originam os granulócitos - neutrófilos, eosinófilos e basófilos - e macrófagos. Por último estas população dá origem a linhagem linfoide, que segue para a formação das células natural killer (NK) e os linfócitos T e B (YE; GRAF, 2007; JAGANNATHAN-BOGDAN; ZON, 2013).

As células da linhagem linfoide são classificadas em dois grandes grupos, de acordo com sua função e especificidade: um composto por grandes linfócitos contendo grânulos em seu citoplasma; e outro por pequenos linfócitos de citoplasma reduzido. Este último grupo pode ainda dividir-se em sublinhagens, de acordo com o local onde se diferenciam (ERGUN et al., 2013). Os linfócitos saem da medula óssea e penetram na corrente sanguínea, sendo transportados até os órgãos linfoides. 
Caso seu destino seja o timo, os linfócitos irão se proliferar e originar os linfócitos $T$. Os linfócitos que não forem expostos ao ambiente tímico e atingirem os demais órgãos e tecidos linfoides darão origem aos linfócitos B (STEVENS; WEISSMAN; BUTCHER, 1982).

Os linfócitos são células migratórias do sistema imune, primordiais no estudo imunológico em qualquer espécie. A partir do estimulo do antígeno, componentes moleculares de agentes exógenos como bactérias e vírus, ambos os tipos de linfócitos passam por uma fase de proliferação e diferenciação, tornando-se assim células de memória e células efetoras (JANEWAY, 2006). As células de memória são mais duradouras, possuindo uma vida útil maior que possibilita o sistema imune a responder de forma mais rápida a ter novos contatos com o antígeno (ZANDI et al., 2008). De forma oposta, as células efetoras atuam diretamente sobre o antígeno, possuindo vida curta e restrita a um evento isolado.

Os linfócitos $\mathrm{B}$ podem seguir dois caminhos a partir do contato com o antígeno, levando assim a formação de células $B$ de memória e células $B$ efetoras (ZANDI et al., 2008). Quando ativados pelo contato com um microorganismo, os linfócitos $B$ proliferam e se diferenciam em células denominadas plasmócitos, produtoras e secretoras de grandes quantidades de anticorpos. Alguns linfócitos $B$ ativados não se diferenciam nesse tipo celular, dando origem às chamadas células $B$ de memória. Estas células possuem vida longa e respondem rapidamente a uma segunda exposição ao mesmo antígeno (BRYDER; SIGVARDSSON, 2010; RAMÍREZ; LUKIN; HAGMAN, 2010; SIGVARDSSON, 2010).

Os linfócitos $\mathrm{T}$, após atingirem o timo e se diferenciarem, podem permanecer no órgão o serem lançadas novamente na corrente sanguínea. As células que permanecem no timo podem originar subpopulações com uma função específica: os $T$ helper, responsáveis pela transformação dos linfócitos $B$ em plasmócitos; os $T$ supressores, que inibem a atividade dos anticorpos de forma a controlar a resposta imune diante do antígeno; os $\mathrm{T}$ citotóxicos, que agem diretamente sobre os componentes estranhos ao organismo, causando sua lise ou apoptose. Os linfócitos T que foram lançados na corrente sanguínea e atingem outros órgãos linfoides são considerados células T de memória (OWEN; RAFF, 1970; LIANG; HOLMES; ZÜÑIGA-PFLÜCKER, 2013). 


\subsection{SISTEMA LINFÁTICO X SISTEMA LINFOIDE}

Os linfócitos não se distribuem de forma homogênea nos tecidos e órgãos linfoides, com exceção do timo, órgão composto exclusivamente por linfócitos $T$ (RAMISCAL; VINUESA, 2013). Este tipo celular pode ser encontrado em órgãos e tecidos de dois grandes sistemas do corpo: o sistema linfático e o linfoide.

O sistema linfático é formado por uma extensa rede de vasos e nódulos linfáticos conhecidos como linfonodos, que são responsáveis pelo transporte do líquido linfático ou linfa, dos tecidos de volta para o sistema circulatório, com o qual está intimamente interligado (DYCE; SACK; WENSING, 2010; KONIG; LIEBICH, 2011). Através dessa remoção de fluidos em excesso, o sistema linfático permite a retirada de antígenos dos tecidos corporais e produz células conhecidas como glóbulos brancos, leucócitos, linfócitos, monócitos e células produtoras de anticorpos conhecidas como plasmócitos (HARVEY, 2012).

O sistema linfoide por sua vez é mais abrangente. Além de englobar o sistema linfático, abrange ainda todas as células, tecidos e órgãos do corpo que contêm agregados linfocitários (EROSCHENKO, 2008). Os tecidos linfoides podem estar distribuídos de forma difusa ou organizada. De acordo com o sistema no qual é encontrado, pode ser classificado como MALT (associado à mucosa), GALT (associado ao sistema gastrointestinal), SALT (associado à pele) e BALT (associado ao sistema respiratório) (BANKS, 1998; BACHA; BACHA, 2000).

Os tecidos linfoides difusos estão distribuídos de forma desorganizada no tecido conjuntivo frouxo de inúmeros sistemas orgânicos. Os tecidos linfoides organizados podem dar origem a agregados celulares que aparecem de forma solitária, como um nódulo linfático não encapsulado, ou de forma múltipla, com a presença de inúmeros nódulos, com comunicação entre si ou não (PRESS; LANDSVERK, 2012). Eles podem ainda originar os chamados órgãos linfoides, nódulos linfáticos encapsulados que possuem características e funções especializadas.

Uma vez encapsulado, o tecido linfoide origina os chamados órgãos linfoides primários ou centrais (timo e medula óssea) e secundários ou periféricos (linfonodos, tonsilas e baço). Nos órgãos primários ocorre a linfopoiese (produção de linfócitos), onde as células diferenciam-se, proliferam e amadurecem em linfócitos T (no timo) e 
B (fígado fetal e medula óssea) (ROLINK et al., 2006). Após o processo de maturação celular, os linfócitos imunocompetentes migram para os chamados órgãos linfoides secundários, onde interagem entre si para produção das respostas imune celular e humoral, onde são geradas as células efetoras e de memória, possibilitando a produção de resposta e memória imunológica (VEJLSTED, 2012).

\subsection{TECIDOS E ÓRGÃOS LINFOIDES EM MAMÍFEROS}

Nos órgãos linfoides primários as células são apresentadas aos antígenos e expressam receptores específicos para estes, produzindo respostas correspondentes ao tipo de agente agressor (PARHAM, 2009). Durante o desenvolvimento fetal, os linfócitos $T$ e $B$ adquirem suas identidades celulares no interior dos chamados órgãos linfoides primários.

Em ruminantes, suínos e alguns roedores, há a presença de nódulos linfáticos agregados ao intestino delgado distal; e em aves há uma bolsa cloacal, chamada bursa de Fabricius, que funcionam como órgãos primários (NAGY; OLÁH, 2007; KOZUKA et al., 2010). O fígado é considerado um órgão linfoide primário durante a vida fetal, dada sua importância no desenvolvimento do sistema imunológico através da hematopoiese embrionária (REECE, 2006; CUNNINGHAM; KLEIN, 2008).

A medula óssea é a principal fonte de células-tronco pluripotentes em mamíferos e o principal sítio de diferenciação dos linfócitos $B$ recém-produzidos (REIDARSON; DUFFIELD; MCBAIN, 2000). Apesar de ser essencial e primordialmente considerada como órgão hematopoiético, ela é considerada um órgão linfoide primário devido ao seu papel na produção dos precursores dos linfócitos B e T. Sua atividade continua por toda a vida dos mamíferos, onde as células sanguíneas são renovadas continuamente (GASPER, 2000).

As células-tronco linfocíticas, atraídas por sinais quimiotáxicos tímicos, migram da medula óssea para o timo e ocupam os espaços presentes no órgão, extremamente ramificado. Com a idade, há uma involução do órgão, onde os timócitos são substituídos gradativamente por células adiposas (BANKS, 1998). Acredita-se que esse processo está relacionado com a ausência de sinais químicos que mantém as células tímicas em atividade e multiplicação (PRESS; LANDSVERK, 
2012). Lubis, Ladds e Reilly (1982) acreditam que esta involução tecidual ocorra não somente no timo, mas em todo o sistema linfoide.

Quando deixam os órgãos linfáticos primários, os linfócitos são considerados imaturos e geralmente são eliminados por apoptose por serem considerados inadequados pelo organismo. Os demais linfócitos se distribuem pelo corpo, atingindo o tecido linfático difuso, assim como os órgãos linfáticos secundários: linfonodos, baço, tonsilas e tecidos linfáticos organizados presentes em outros sistemas, tais como o MALT e GALT (EROSCHENKO, 2008).

Os tecidos e órgãos linfoides secundários formam-se no final da vida fetal e persistem por toda a vida adulta (HYTTEL, 2012). Estes se diferenciam dos órgãos primários pela sua capacidade em aumentar de tamanho diante de um estímulo imunológico, em resposta a presença de um antígeno.

\subsection{SISTEMA LINFOIDE EM MAMÍFEROS AQUÁTICOS}

A morfologia dos órgãos linfoides em mamíferos aquáticos é semelhante aos dos demais mamíferos (SIMPSON; GARDNER, 1972). No entanto, podem ser observadas algumas particularidades nos órgãos e tecidos linfoides secundários, tais como a ausência de ceco e apêndice, considerados de importância no sistema linfoide devido à presença de grandes aglomerados de tecido linfoide nestas regiões (GREEN, 1972; PABST; ROMMEL; MCLELLAN, 1999) e a presença de agregados linfoepiteliais nas regiões orofaríngea e anal (COWAN, 1994; SMITH; TURNBULL; COWAN, 1999), denominadas tonsilas.

Smith, Turnbull e Cowan (1999) afirmar que a função da tonsila orofaríngea ainda permanece incerta, porém autores afirmam que a resposta imune desta estrutura funciona de forma paralela e complementar a dos linfonodos presentes na região, uma vez que sua posição anatômica - no interior e na base da laringe, ocupando o espaço no diâmetro das vias aéreas - não afeta de forma significativa a passagem de ar, mesmo em animais com aumento dos linfonodos associado a infecções respiratórias. Essa estrutura linfoepitelial foi primeiramente descrita na laringe de Mesoplodon (ANTHONY; COUPIN, 1930), sendo relatado posteriormente 
em Orcella (ANDERSON, 1878), Phocoena phocoena (BEHRMANN, 1987) e $T$. truncatus (SMITH; TURNBULL; COWAN, 1999).

O trato respiratório dos cetáceos tem sido modificado evolutivamente para uma melhor adaptação a vida aquática (BERTA; SUMICH, 1999). Devido à ausência de seios nasais, possivelmente uma adaptação para o mergulho (REIDENBERG; LAITMAN, 2008), a localização da tonsila orofaríngea seria estratégica nestes animais. Com a separação extensa dos sistemas respiratório e gastrointestinal, acredita-se que sua localização incomum e sua superfície rugosa permitam a apresentação e expulsão de antígenos, respectivamente durante a inalação. $\mathrm{O}$ ar inspirado pelo respiradouro segue quase que diretamente pela nasofaringe até atingir a laringe, traqueia e pulmões (PABST; ROMMEL; MCLELLAN, 1999; ROMMEL; LOWENSTINE, 2001). Esta estrutura funcionaria de forma homóloga à adenoide, estrutura nasofaríngea em humanos que compõem o anel de Waldeyer (HELLINGS; JORISSEN; CEUPPENS, 2000).

Outra adaptação que levanta questionamentos é a presença de um órgão linfoepitelial mucoso no canal anal de algumas espécies de cetáceos, denominada tonsila anal, como relatada para Physeter catodon (UYS; BEST, 1966), Eschrichtius robustus (COWAN; BROWNELL, 1974), Platanista gangetica (YAMASAKI; KOMATSU; KAMIJA, 1977), Stenella coeruleoalba (KOMATSU, 1979), Steno bredanensis, Lagenodelphis hosei e T. truncatus (COWAN; SMITH, 1995). Apesar da descrição em inúmeras espécies, esta não é considerada universal entre os cetáceos (YAMASAKI; TAKAHASHI; KAMIJA, 1975; YAMASAKI; KOMATSU; KAMIJA, 1977; CAVE, 1980; ROMANO et al., 1993).

Segundo Beineke et al. (2010), esta estrutura, pode estar envolvida na apresentação de antígeno devido ao refluxo retal de água durante o mergulho. Uma vez que os cetáceos não possuem ceco ou apêndice, a tonsila anal poderia substituir algumas das funções destas estruturas anatômicas (COWAN; SMITH, 1995). A depleção no número de linfócitos nesta tonsila inicia-se após a puberdade e juntamente com a diminuição progressiva na atividade imune, é vista como uma involução do órgão, assim como verificado no timo (COWAN, 1994).

Essa depleção, relacionada à idade e comum em mamíferos (CHINN et al., 2012), também é verificada em outros tecidos linfoides secundários, como os tecidos linfoides associados à mucosa (MALT) e associados ao trato gastrointestinal, conhecidos como placas de Peyer para todas as espécies de mamíferos desde sua 
descoberta em 1677 por J. C. Peyer. A GALT é bem desenvolvida em mamíferos aquáticos e foi primeiramente descrita em peixe-boi amazônico por Beddard (1897). A ocorrência das MALT e GALT, assim como da tonsila anal, não pode ser vista como uma adaptação à vida aquática, uma vez que estes tecidos podem ser encontrados em inúmeras espécies de mamíferos terrestres (PASTORET et al., 1998), como bovinos, caprinos e suínos (LOWDEN; HEATH, 1995; SONI et al., 2006; ROTHKÖTTER, 2009; MERCHANT et al., 2011).

Simpson e Gardner (1972) descreveram este tecido em cetáceos, como o $T$. truncatus, Stenella longirostris, Inia geofrensis e Globicephala melas, sem, no entanto, fazer menção de quais espécies este tecido foi encontrado e com qual grau de desenvolvimento. Em Delphinapterus leucas, Romano et al. (1993) verificaram a presença de agregados linfocitários na submucosa e lâmina própria do intestino, sem formação de placas de Peyer, com presença de MALT mais proeminente no TGI distal. Em contraste, grandes placas de Peyer confluentes foram verificadas no intestino de T, truncatus (COWAN; SMITH, 1999).

A distribuição destes tecidos linfoides no trato gastrointestinal é aleatória entre interespécies e não apresenta relação com idade ou sexo. No entanto, Cowan e Smith $(1995,1999)$ afirmam que em adultos há uma atrofia linfocítica e formação de dilatação cística das tonsilas anais, parte do processo fisiológico inerente à idade, que também pode ser verificado nos MALT. Segundo Clark, Turner e Cowan (2005) há uma involução quase completa deste tecido linfoide na região do cólon de $T$. truncatus mais velhos.

Essa mesma involução pode ser observada no tecido tímico. Assim como nos demais mamíferos terrestres, o timo em cetáceos é um órgão que pode ser encontrado facilmente em filhotes e animais jovens, estando na maioria das vezes ausente em adultos. Essa involução tímica é considerada um processo progressivo lento relacionado à idade e para Wünschmann, Siebert e Frese (1999), está intimamente ligado com a degeneração dos corpúsculos de Hassal e/ou condensação do retículo epitelial tímico, achado comum em $P$. phocoena.

Há relatos de que há a presença de remanescentes de tecido tímico em adultos saudáveis de $P$. phocoena e $T$. truncatus (BEINEKE et al., 2010) e que muitas vezes é difícil distinguir macroscopicamente um timo em involução de tecido adiposo. Ainda existe discordância entre os pesquisadores se a involução cística do timo está relacionada somente com a idade (COWAN, 1994) ou se pode refletir o 
tempo de exposição a contaminantes presentes no meio ambiente de forma imperceptível (BEINEKE et al., 2005; BEINEKE; SIEBERT; BAUMGARTNER, 2006).

No que se refere aos linfonodos, a arquitetura está de acordo com os achados em outros mamíferos aquáticos da ordem Cetacea, com exceção das espécies Delphinus delphis e $P$. phocoena, que apresentam disposição córtex-medula contrária aos padrões das espécies de mamíferos e semelhante ao observado em equinos e suínos (BANKS, 1998, BACHA; BACHA, 2000, PRESS; LANDSVERK, 2012). Algumas adaptações estão presentes no linfonodo de golfinhos e baleias, como a presença de fibras de músculo liso na camada subcapsular de alguns linfonodos viscerais. Romano et al. (1993) e Cowan e Smith (1999) sugerem que tal característica possibilitaria um movimento ativo do órgão, potencializando a filtração do fluido linfático por meio da contração capsular destes linfonodos.

Microscopicamente, este órgão linfoide também apresenta outras particularidades, como a presença de centros germinativos mais evidentes e em maior número em animais jovens, sendo às vezes imperceptível em animais adultos (CAVAGNOLO, 1979). Para Simpson e Gardner (1972) isto se explica pela aparente hiporreatividade dos tecidos linfoides secundários em mamíferos aquáticos. Isto não implica necessariamente em uma resposta imune inadequada, como o sugerido por Romano et al. (1993), podendo esta estar ligada diretamente a sanidade em conjunto com a idade dos animais e a exposição a antígenos capazes de estimulálos imunologicamente.

O baço de cetáceos é um órgão simples, de tamanho reduzido quando comparado aos demais órgãos ( $0,2 \%$ do peso corpóreo do animal), o que limita sua capacidade de armazenamento sanguíneo (SLIJPER, 1958; BRYDEN, 1972). Por conta de seu tamanho diminuto, o baço de cetáceos não podem ser classificados como de armazenamento, como o de mamíferos terrestres. Zwillenberg (1960) acredita que o baço de odontocetos e misticetos não possui uma denominação clássica como em humanos e mamíferos terrestres e que em $P$. phocoena foram encontradas fibras contráteis trabeculares e capsulares, o que tornaria o órgão um reservatório. Cowan e Smith (1999) afirmam haver hematopoiese extramedular no tecido esplênico de $T$. truncatus e sua superfície irregular permite que este acomode grande quantidade de sangue, classificando o órgão na mesma categoria (PILLERI; ARVY, 1971). 
O baço também não pode ser classificado como metabólico (caso do baço humano) onde os tecidos linfoides são bem desenvolvidos. Tal característica em cetáceos é vista apenas em animais jovens, onde a polpa branca, bem desenvolvida, é formada predominantemente por nódulos linfáticos circundados pela bainha linfoide periarteriolar. Em animais com idade mais avançada, estes centros foliculares são raros e pouco desenvolvidos (ROMANO et al., 1993). Simpson e Gardner (1972) afirmam que a baixa quantidade de nódulos linfáticos pode afetar a sanidade de animais mais velhos caso este seja exposto a agentes infecciosos. Assim como em linfonodos, não é esclarecido se há uma baixa imunoatividade deste órgão em mamíferos aquáticos. 


\section{OBJETIVOS}

\subsection{GERAL}

- Descrever a morfologia dos órgãos linfoides em cetáceos (Subordem Odontoceti) encalhados nas regiões norte e nordeste do Brasil, machos e fêmeas de diferentes faixas etárias.

\subsection{ESPECÍFICOS}

- Descrever os aspectos macroscópicos do timo, baço, linfonodos, placas de Peyer (intestinos grosso e delgado), tecidos linfoides associados a mucosa e tonsilas orofaríngeas e anal das espécies Sotalia guianensis, Sotalia fluviatilis, Stenella clymene, Stenella longirostris, Inia geofrensis, Peponocephala electra e Globicephala macrorhynchus;

- Descrever microscopicamente os referidos órgãos, utilizando diferentes técnicas: microscopia de luz, eletrônica de varredura e transmissão, e imunohistoquímica;

- Utilizar a histomorfometria e/ou análise estatística quantitativa, sempre que possível, para avaliar a presença de diferenças entre as espécies, faixas etárias e sexo. 


\section{MATERIAIS E MÉTODO}

A pesquisa foi realizada de acordo com as normas da Comissão de Bioética da Faculdade de Medicina Veterinária e Zootecnia da Universidade de São Paulo (Protocolo 2571/2012) e com autorização do Instituto Chico Mendes de Conservação da Biodiversidade (ICMBio) para coleta e transporte de material biológico com finalidade científica (Licenças Sisbio 37369-1 e 37369-2, Anexos A e B).

\subsection{ANIMAIS E AMOSTRAS}

Foram analisados um total de 71 exemplares de odontocetos, sendo Sotalia guianensis $(n=24)$, Sotalia fluviatilis $(n=09)$, Stenella clymene $(n=13)$, Stenella longirostris $(n=05)$, Inia geofrensis $(n=4)$, Peponocephala electra $(n=13)$ e Globicephala macrorhynchus ( $n=03$ ), oriundos de eventos de encalhes nas regiões norte e nordeste do Brasil, de ambos os sexos e diferentes grupos etários (filhote, jovem e adulto). Os grupos etários foram definidos com base na dentição e/ou comprimento corpóreo total dos animais (JEFFERSON; LEATHERWOOD; WEBBER, 1993).

Foram estudados os órgãos timo, baço, linfonodos, placas de Peyer (intestinos grosso e delgado), tonsilas orofaríngea e anal, bem como os tecidos linfoides associados à mucosa da pele, sistema genital feminino e vasos sanguíneos. As amostras biológicas foram obtidas nos acervos úmidos de Organizações Não Governamentais: Fundação Mamíferos Aquáticos - FMA (Sergipe), Associação de Pesquisa e Preservação de Ecossistemas Aquáticos - AQUASIS (Ceará), Instituto Biota de Conservação - BIOTA (Alagoas) e a Organização Social, Instituto de Desenvolvimento Sustentável Mamirauá - IDSM (Amazonas).

Inicialmente, antes da obtenção de amostras biológicas, todas as carcaças foram avaliadas para determinar seu estado de decomposição. Posteriormente, as mesmas foram classificadas dentro de cinco categorias básicas (CODES), conforme sugerido por Geraci e Lounsbury (2005). 
Estas categorias foram definidas tendo como base características específicas: CODES 1 para animal vivo; CODES 2 para carcaça em boas condições; CODES 3 para carcaça em estado razoável; CODES 4 para carcaça em decomposição avançada; e CODES 5 para carcaça mumificada ou restos de esqueleto. Apenas espécimes CODES 2 e 3 foram usados no estudo.

\subsection{NECROPSIA E ANÁLISE MACROSCÓPICA}

Os animais foram posicionados em decúbito lateral direito e uma incisão foi realizada no flanco esquerdo para remoção da pele e tecido adiposo. Dois cortes adicionais foram feitos perpendicularmente ao meio do flanco, nas regiões umbilical e anal. Um quarto corte foi feito paralelamente ao corpo, formando um quadrilátero ("janela") para permitir o acesso às vísceras abdominais. Um quinto corte foi feito para permitir o acesso aos órgãos torácicos (REYNOLDS; ROMMEL; BOLEN, 2002).

Ambas as cavidades, torácicas e abdominal, foram examinadas para localização dos órgãos de interesse in loco, possibilitando a exposição do intestino, bem como a identificação de quaisquer tecidos linfoides associados à mucosa nasofaríngea, pele, vasos sanguíneos, sistema respiratório e trato gastrointestinal. Foram coletadas amostras de intestino aleatoriamente, entretanto por motivos didáticos, optou-se por dividir o intestino em terço inicial (proximal) e médio (medial) como intestino delgado devido a sua estrutura mais delgada, e terço final (distal) como intestino grosso, uma vez que seu epitélio é diferenciado quando comparado ao demais terços intestinais.

Todos os órgãos foram identificados, fotodocumentados e dissecados. Após, pequenas amostras de tecidos foram coletadas, lavadas e fixadas em formol $10 \%$ para microscopia de luz e eletrônica de varredura e imunohistoquímica e solução de Karnovsky modificada (2,5\% de glutaraldeído e $2 \%$ de paraformaldeído em solução tampão fosfato de sódio a $0,1 \mathrm{M}$ e $\mathrm{pH} 7,4)$ para microscopia eletrônica de transmissão. 


\subsection{ANÁLISES MICROSCÓPICAS}

Para análise microscópica de luz, as amostras foram lavadas em água corrente após a fixação, desidratadas em soluções crescentes de etanol (70\% a $100 \%)$, diafanizadas em xilol e incluídas em Paraplast $\AA^{\circledR}$. As secções $(6 \mu \mathrm{m})$ foram coradas por técnicas de Hematoxilina-Eosina, Tricrômio de Masson e Tricrômio de Mallory e as lâminas foram capturadas e analisadas ao microscópio de luz (Nikon Eclipse E800).

Para análise de microscopia eletrônica de varredura, as amostras foram submetidas à lavagem em água destilada (3x 10', sob rotação), posteriormente desidratadas em série crescente de etanol sob rotação [70\% (1× 15'); 80\% (1×15'); $90 \%$ ( $\left.1 \times 15^{\prime}\right)$ e $100 \%(3 \times 30$ )], secas em aparelho ponto crítico, montadas em bases metálicas de alumínio (stub), utilizando cola de carbono, e cobertas com ouro por sputting. As amostras foram então analisadas no microscópio eletrônico de varredura (LEO 435 VP).

Os tecidos para microscopia eletrônica de transmissão foram seccionados em fragmentos menores $(0,2-0,3 \mathrm{~cm})$ e pós-fixados em solução de tetróxido de ósmio a $1 \%$ em solução tampão fosfato de sódio durante 2 horas a $4^{\circ} \mathrm{C}$. Em seguida, os tecidos foram desidratados em séries crescentes de alcoóis (60-100\%) e embebidos em solução de óxido de propileno e resina Spurr (proporção 1:1; 6h à temperatura ambiente).

Posteriormente, estas foram substituídas por resina pura durante 6 horas, após foram inclusas em resina pura em moldes de borracha e levados à estufa para polimerização (36h). Após a polimerização, foi realizada a triagem dos blocos e a obtenção de cortes de 1-3 $\mu \mathrm{m}$ em ultramicrótomo. As secções foram coradas em azul de toluidina para exame ao microscópio de luz e localização das áreas de interesse. Cortes ultrafinos $(90 \mathrm{~nm})$ foram obtidos com faca de diamante e coletados em telas de 200 'mesh', que após foram contrastadas com solução de acetato de uralina a $4 \%$ e citrato de chumbo a $0,4 \%$, examinadas e capturadas em microscópio eletrônico de transmissão (JEOL-JSM 6100). 


\subsection{IMUNOHISTOQUÍMICA}

Para marcação de linfócitos, optou-se pela marcação de linfócitos T CD3 através de análise imunohistoquímica, seguindo o descrito por Beineke et al. (2001). Secções $(5 \mu \mathrm{m})$ foram desparafinizadas e reidratadas antes do início do protocolo. Os tecidos foram pré-tratados com tampão de recuperação antigênica (Tris/EDTA/Tween) por $20 \mathrm{~min}$ a $96^{\circ} \mathrm{C}$. Após resfriar em temperatura ambiente, foram feitas lavagens em TBS (tampão TBS-HCL/Tween).

Após recuperação, a área do tecido foi delimitada com caneta hidrofóbica e foi feito bloqueio da peroxidase endógena com $\mathrm{H}_{2} \mathrm{O}_{2} 3 \%$ por $15 \mathrm{~min}$ em temperatura ambiente (TA). As lâminas foram então lavadas em água corrente, seguida por água destilada e TBS. Para bloqueio de proteínas, utilizou-se a solução Goat Serum 2,5\% (Kit ImmPRESS HRP Anti-Rat Ig, Mouse adsorbed, Vector Laboratories, USA) por $20 \mathrm{~min}, \mathrm{TA}$. Após incubação, os tecidos foram lavados em TBS para aplicação do anticorpo primário (concentração 1:200; MCA1477 - Rat Anti Human CD3, ABDSerotec, USA), permanecendo em câmara úmida overnight a $4^{\circ} \mathrm{C}$.

As lâminas foram então lavadas em TBS para incubação com Immpress Reagent (Kit ImmPRESS HRP Anti-Rat Ig, Mouse adsorbed, Vector Laboratories, USA) por 20-30min em TA. Após lavagem, procedeu-se com a revelação da reação (Cromógeno ImmPACT ${ }^{\mathrm{TM}}$ DAB, Vector Laboratories, USA). Os tecidos foram lavados em água corrente, contra-corados com hematoxilina e as lâminas montadas com Permount.

\subsection{HISTOMORFOMETRIA}

Linfonodos mesentéricos foram avaliados por estereologia a fim de avaliar a densidade de volume vascular (VV) e de comprimento vascular (CV). Estes linfonodos foram escolhidos devido à grande quantidade destes obtidas durante as necropsias e à sua ocorrência em todas as espécies estudadas, fornecendo assim uma análise estatística mais confiável. 
Para analise por estereologia foram utilizadas as lâminas de microscopia de luz através do programa de sobreposição Stepanizer (TSCHANZ; BURRI; WEIBEL, 2011). As imagens das cápsulas de linfonodos foram analisadas para contagem dos vasos sanguíneos em uma área conhecida, denominada de área de teste (TA). A fim de evitar superestimativa dos vasos, estabeleceu-se uma regra básica: no campo a ser contado, definido como um quadrado, duas linhas (bordas esquerda e inferior) foram consideradas como proibidas para a contagem de quaisquer vasos tocandoas, e duas linhas (borda direita e superior) foram consideradas como permitidas para a contagem de vasos.

A variável $V V$, expressa como percentagem (\%), foi estimada de acordo com a fórmula: $\mathrm{VV}=\mathrm{PTT} / \mathrm{Tpt}$ [PTT: número de pontos de teste que tocam os vasos; Tpt: número total de pontos de teste no sistema (100)]. A variável $C V$, expressa em $\mathrm{mm} / \mathrm{mm}^{3}$, foi estimada de acordo com a fórmula: $\mathrm{CV}=2^{(\mathrm{N} / \mathrm{AT})}$ [n: número de vasos sanguíneos dentro da área teste; AT: área de teste $\left.\left(45.692,65 \mathrm{~mm}^{2}\right)\right]$.

Os dados foram distribuídos de forma paramétrica, Sendo assim, os testes One Way ANOVA seguido de Tukey- Kramer pós-teste para comparações múltiplas (GraphPad Prism 5 Software) foram aplicados entre os diferentes grupos etários (filhotes, jovens e adultos). Os resultados foram apresentados como média \pm desvio padrão $(P<0,05)$. 


\section{RESULTADOS}

\subsection{MORFOLOGIA DOS LINFONODOS, BAÇO E TIMO}

Os resultados do presente estudo originaram três trabalhos científicos, sendo que todos já se encontram publicados e/ou disponíveis online $(n=2)$ ou em fase final de publicação $(n=1)$. Em decorrência da detenção dos direitos autorais por parte dos Periódicos responsáveis pela publicação dos mesmos, não foi possível descrever os resultados obtidos na presente tese.

O estudo da topografia e morfologia dos linfonodos originou o artigo intitulado "Morphological analysis of lymph nodes in Odontocetes from North and Northeast coast of Brazil” (SILVA et al., 2014a, Anexo C).

$O$ artigo sobre a morfologia do baço intitulado "Accessory spleen in cetaceans and its relevance as a secondary lymphoid organ" (SILVA et al., 2014b, Anexo D).

Já a descrição do timo originou o capítulo de livro intitulado "Microscopic study of the thymus of Guiana dolphin and Humpback whale"1.

\subsection{MORFOLOGIA DOS TECIDOS LINFOIDES ASSOCIADOS À MUCOSA}

Foram analisados os tecidos linfoides associados à mucosa de 46 animais, sendo 24 Sotalia guianensis (boto-cinza), 6 Sotalia fluviatilis (tucuxi), 4 Stenella clymene (golfinho-climene), 6 Inia geofrensis (boto-vermelho), 2 Peponocephala electra (golfinho-cabeça-de-melão) e 2 Globicephala macrorhynchus (baleia-pilotode-peitorais-curtas).

${ }^{1}$ SILVA, F. M. O. Microscopy Advances in Scientific Research and Education, a ser publicado pela Formatex Research Center. 
Tabela 1 - Lista de amostras coletadas por espécie, de acordo com o sexo e o grupo etário ${ }^{1}$ (jovem:filhote:adulto).

\begin{tabular}{lccc}
\hline Espécies & $\begin{array}{c}\mathrm{N}^{\circ} \text { de } \\
\text { machos/grupo } \\
\text { etário }\end{array}$ & $\begin{array}{c}\mathrm{N}^{\circ} \text { de } \\
\text { fêmeas/grupo } \\
\text { etário }\end{array}$ & $\begin{array}{c}\mathrm{N}^{\circ} \text { total de animais } \\
\text { avaliados }\end{array}$ \\
\hline $\begin{array}{l}\text { Inia geoffrensis } \\
\text { Globicephala macrorhynchus }\end{array}$ & $\begin{array}{l}0: 1: 3 \\
\text { Peponocephala electra }\end{array}$ & $1: 0: 1$ & 6 \\
Sotalia guianensis & $0: 2: 0$ & - & 2 \\
Sotalia fluviatilis & $4: 4: 2$ & $3: 6: 4$ & 2 \\
Stenella clymene & $0: 2: 0$ & $0: 4: 0$ & 24 \\
Stenella longirostris & $0: 0: 2$ & $0: 0: 2$ & 6 \\
Total & $0: 0: 1$ & $0: 0: 1$ & 4 \\
T'Grupo etário definido de acordo com o preconizado por Jefferson, Leatherwood e Webber (1993); \\
'Foi avaliado um feto macho, em terço final de gestação, totalizando 24 amostras desta espécie e 46 \\
no total.
\end{tabular}

\subsubsection{Tonsila orofaríngea}

A tonsila orofaríngea (TO) era composta macroscopicamente por uma massa oval palpável, localizada na região ventral à cartilagem cricóide da laringe. Sua estrutura é altamente trabeculada, decorrente do espessamento da mucosa, e pela presença de pequenas fossas e fendas não profundas (Figura 1A).

Em animais jovens observou-se que a TO era maior e mais evidente quando comparada aos animais adultos. Não foi possível avaliar a diferença entre sexos uma vez que o número de espécimes disponíveis para tal análise era reduzido.

Histologicamente, a TO era composta por um complexo linfoepitelial, constituída por epitélio colunar pseudoestratificado não-ciliado (Figura 1C) e invaginações superficiais, que adentram o tecido conjuntivo adjacente, formando criptas (Figura 1B). Junto às criptas, os linfócitos estavam presentes de forma organizada, em forma de nódulos linfáticos com centros germinativos em sua área central (Figura 1B, 1C e 1D), ou desorganizada, onde o infiltrado linfocitário permease pelo tecido conjuntivo, tornando difícil de visualizar o limite entre o tecido conjuntivo e o linfoide (Figura 1C e 1D). Inúmeros linfócitos $T$ foram verificados próximos ao epitélio de revestimento (Figuras 1E e 1F). 
Figura 1 - Tonsila orofaríngea de Odontocetos
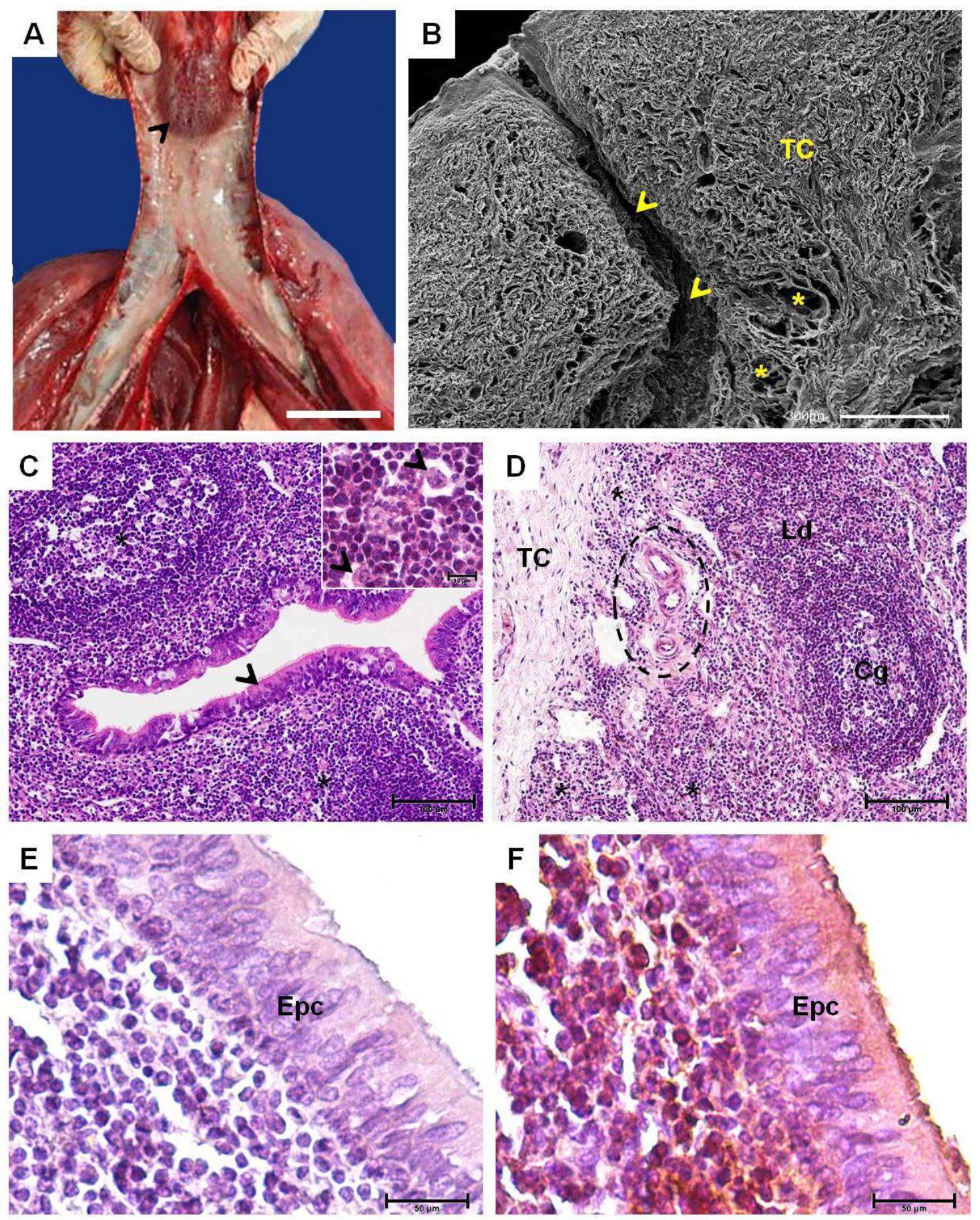

Fonte: (Silva, F. M. O., 2014)

Legenda: Figura A. Tonsila orofaríngea (cabeça de seta) de Peponocephala electra jovem. Barra: $1,5 \mathrm{~cm}$. B-D. Fotomicrografias de tonsila orofaríngea de filhotes de Sotalia guianensis. B. Microscopia eletrônica de varredura. Ducto da cripta (cabeças de seta), circundada por tecido conjuntivo (TC). Cripta coberta por aglomerados de linfócitos $\left(^{*}\right)$. E. C. Tecido epitelial pseudoestratificado colunar (cabeça de seta) na luz da fenda tonsilar. Linfócitos organizados em nódulos linfáticos $\left({ }^{*}\right)$. HE. 40x. Área em maior aumento com linfoblastos indicados por cabeça de seta. HE. 100x. D. Nódulo linfático com centro germinativo evidente $(\mathrm{Cg})$. Presença de linfócitos desorganizados, concentrados densamente $(\mathrm{Ld})$ próximo ao $\mathrm{Cg}$ ou de forma difusa, adentrando o tecido conjuntivo adjacente $\left(^{*}\right)$. Vasos sanguíneos em destaque. HE. 20x. E, F. Imunohistoquímica. E. Controle negativo. F. Marcação de linfócitos T CD3, de cor amarronzadas, próximo ao epitélio pseudoestratificado cilíndrico (Epc) que reveste a cripta. Contracoloração com hematoxilina. 40x. 


\subsubsection{Tecido linfoide associado à pele}

Foram encontradas coleções densas de linfócitos na pele de feto e filhote de Sotalia guianensis, ambos machos. Todos os aglomerados linfoides estavam localizados entre a epiderme e derme, próximos a lâmina própria (Figuras $2 \mathrm{~A}, 2 \mathrm{E}$ e $2 \mathrm{~F})$.

\subsubsection{Tecido linfoide associado ao sistema genital feminino}

Aglomerados de tecido linfoide próximos à lâmina própria da cérvix uterina foram observados em um exemplar jovem de Sotalia guianensis, em fase reprodutiva. A cérvix, de superfície pregueada, era formada pelas camadas: mucosa (revestida por epitélio colunar simples), mucosa e serosa (Figura 2A e 2B).

\subsubsection{Tecido linfoide associado aos vasos sanguíneos}

Junto à artéria pulmonar de uma fêmea de Sotalia guianensis adulta foram observados aglomerados de tecido linfoide, onde os linfócitos encontravam-se organizados, sendo circundados por uma camada de fibras colágenas, desorganizadas de forma a não caracterizarem uma cápsula (Figura 2). 
Figura 2 - Fotomicrografia de tecidos linfoides associados à mucosa.
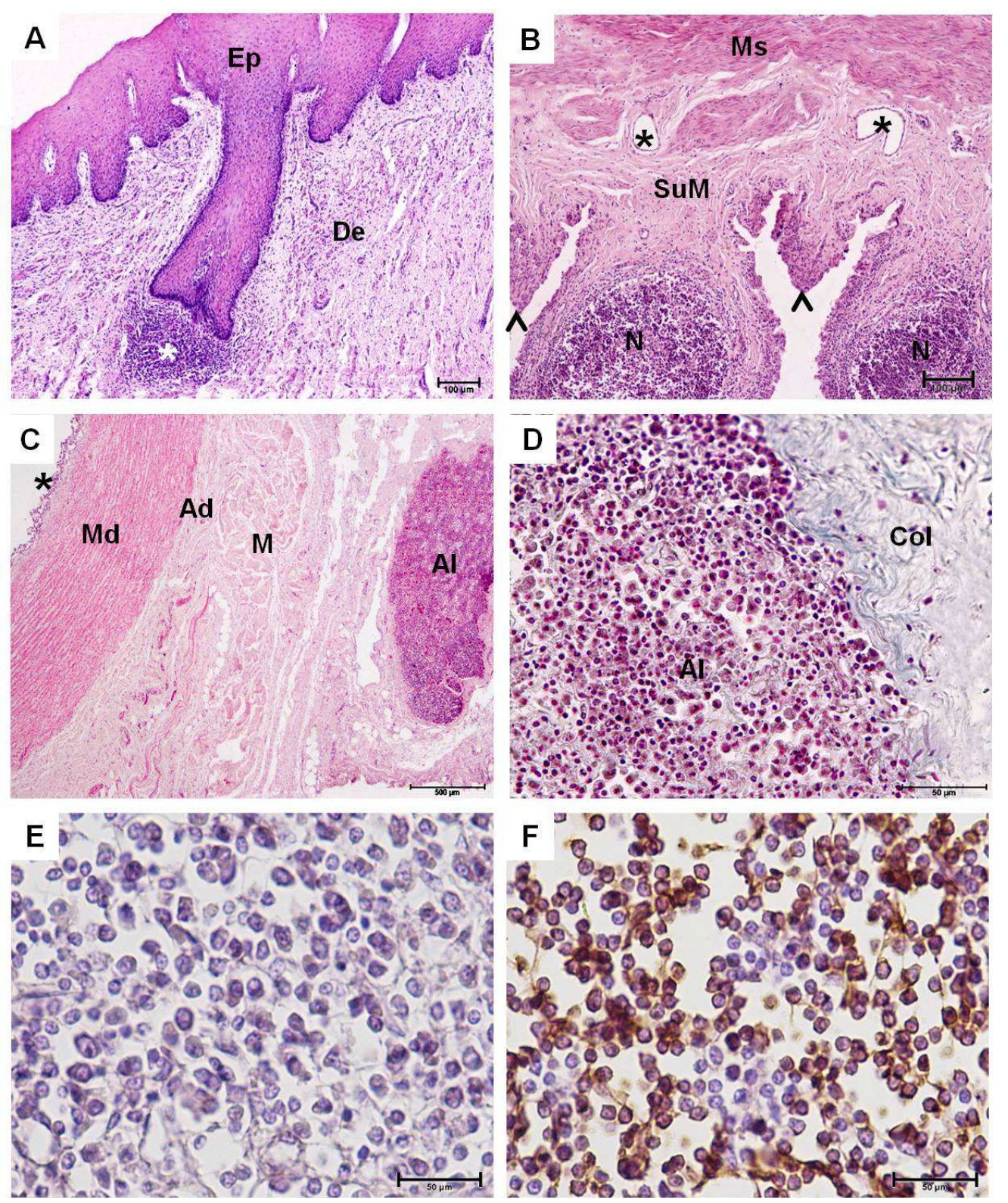

Fonte: (SILVA, F. M. O., 2014)

Legenda: Figura 2. Fotomicrografia de tecidos linfoides associados à mucosa. A. Pele de filhote de Sotalia guianensis. Epitélio (Ep), com papila dérmica terminando em um aglomerado de tecido linfoide $\left(^{*}\right)$ na derme (De). Hematoxilina-eosina (HE). B. Cérvix uterina de Sotalia guianensis jovem. Presença de pregas (cabeças de seta) em sua superfície. Vasos sanguíneos $\left({ }^{*}\right)$ na camada submucosa (SuM), seguida pela camada Muscular (Ms). HE. 10x. C. Artéria pulmonar de Sotalia guianensis adulta. Lúmen ( $\left.{ }^{*}\right)$, camada média (Md) e camada adventícia (Ad). Aglomerado linfoide (Al) adjacente à camada de músculo cardíaco (M). HE. 4x. D. Aglomerado linfoide (Al) em maior aumento, circundado por fibras colágenas (Col). Tricrômio de Masson. 40x. E, F. Imunohistoquímica. Aglomerado linfoide presente na pele de um Globicephala macrorhynchus jovem. E. Controle negativo. F. Marcação de linfócitos T CD3, de cor amarronzadas, em meio a linfócitos B. Contracoloração com Hematoxilina. 40x. 


\subsubsection{Tecido linfoide associado ao trato gastrointestinal}

Os tecidos linfoides associados ao trato gastrointestinal (GALT) eram compostos por aglomerações de linfócitos presentes nas alças intestinais ao redor do lúmen (Figura 3B) de forma difusa (Figura 3C, 3D e 3E) ou em uma região circunscrita (organizado).

Figura 3 - Intestinos e tecidos linfoides associados ao trato gastrointestinal em Odontocetos
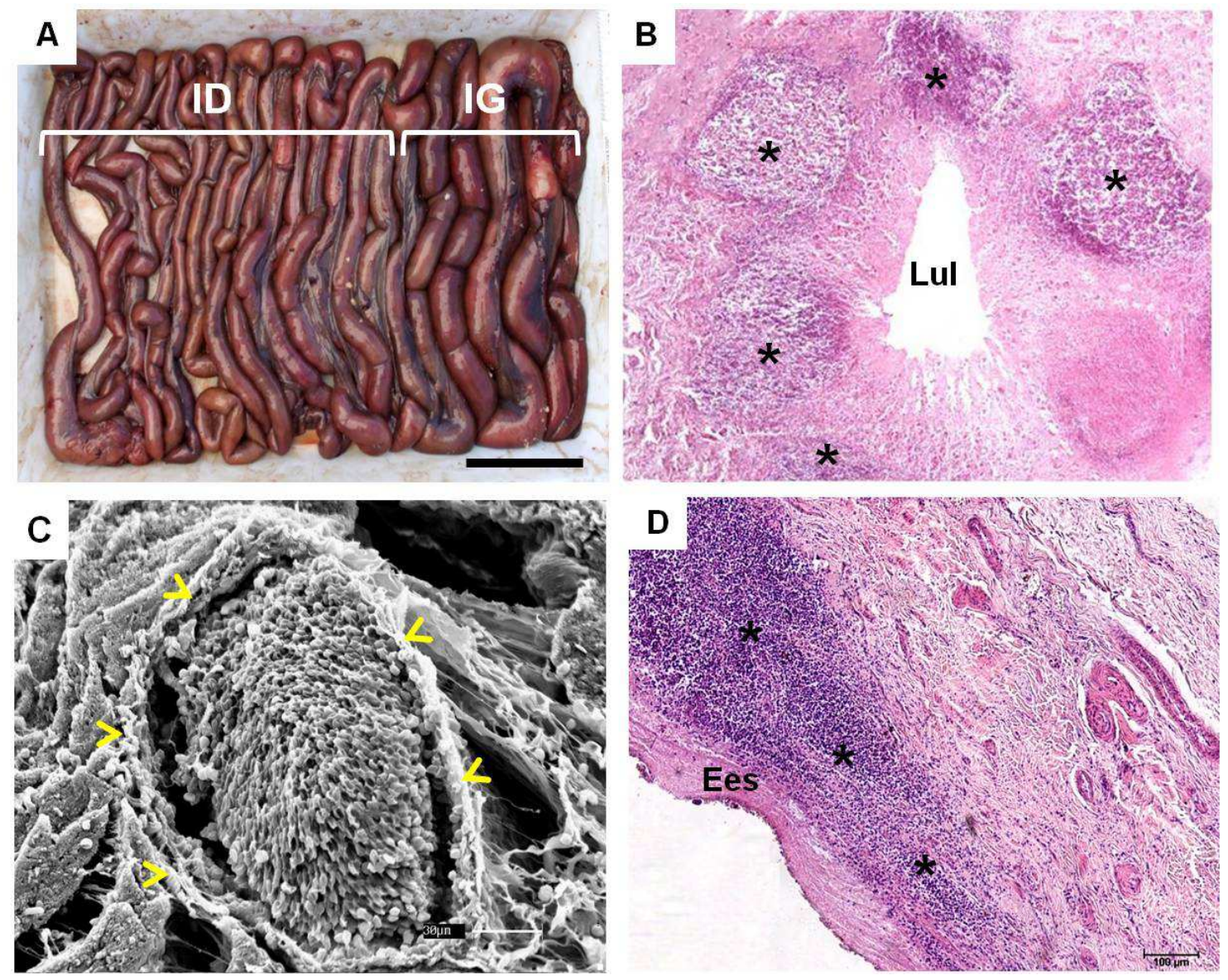

Fonte: (SILVA, F. M. O., 2014)

Legenda: Figura 3. A. Delimitação estimada dos intestinos delgado (ID) e grosso (IG) de Sotalia guianensis. Barra: $3 \mathrm{~cm}$. B-D. Fotomicrografias de diferentes porções do intestino de Odontocetos. B. Terço inicial. Filhote de Sotalia guianensis. Agregação de nódulos linfáticos ${ }^{*}$ ) circundando o lúmen intestinal (Lul). Hematoxilina-eosina (HE). 4x. C. Fotomicrografia eletrônica de varredura do terço médio de intestino de Inia geofrensis. Tecido linfoide delimitado por fibras colágenas densamente organizadas, indicadas por cabeças de seta. D. Terço final. Sotalia guianensis adulto. Epitélio estratificado escamoso (Ees) retal, seguido por uma lâmina de tecido linfoide difuso $\left(^{*}\right)$. HE. 10x. 
O GALT organizado foi verificado na maioria dos casos de placas de Peyer (PP) devido à sua aparência distinta, caracterizada por verdadeiros agregados de linfócitos que formaram uma saliência que muitas vezes adentraram o lúmen intestinal (Figura 4A). As PPs eram como estruturas de formato redondo, oval ou irregulares (Figura 4B e $4 \mathrm{C}$ ), onde os linfócitos reuniram-se dando origem ao chamado nódulo linfático (Figura). As PP variaram em tamanho e quantidade, estando presentes em maior quantidade nos terços inicial e médio, principalmente em animais jovens quando comparado a animais adultos. Não houve variação quanto ao sexo no que diz respeito à quantidade ou tamanho das GALT.

Em alguns filhotes os nódulos linfáticos apresentaram sua região central mais fracamente corada. Esta fraca coloração deve-se a presença de inúmeros linfoblastos, células em proliferação que possuem maior tamanho e núcleo menos heterocromático quando comparadas aos linfócitos (Figura 4E). Estes nódulos linfáticos não foram capsulados, sendo delimitados por fibras colágenas densamente organizadas (Figura 4F).

As PP apresentaram-se como nódulos linfáticos solitários (Figura 5A e 5B), próximos uns aos outros (Figuras $5 \mathrm{C}$ e $5 \mathrm{D}$ ) ou agregados/ ligados uns aos outros (Figura 5E). Em alguns casos as vilosidades intestinais estavam ausentes no local onde os ductos linfáticos "desembocavam" na superfície da mucosa em direção ao lúmen intestinal (Figuras 5B, 5C e 5F). 
Figura 4 - Intestino e tecido linfoide associado à mucosa gastrointestina em Inia geofrensis
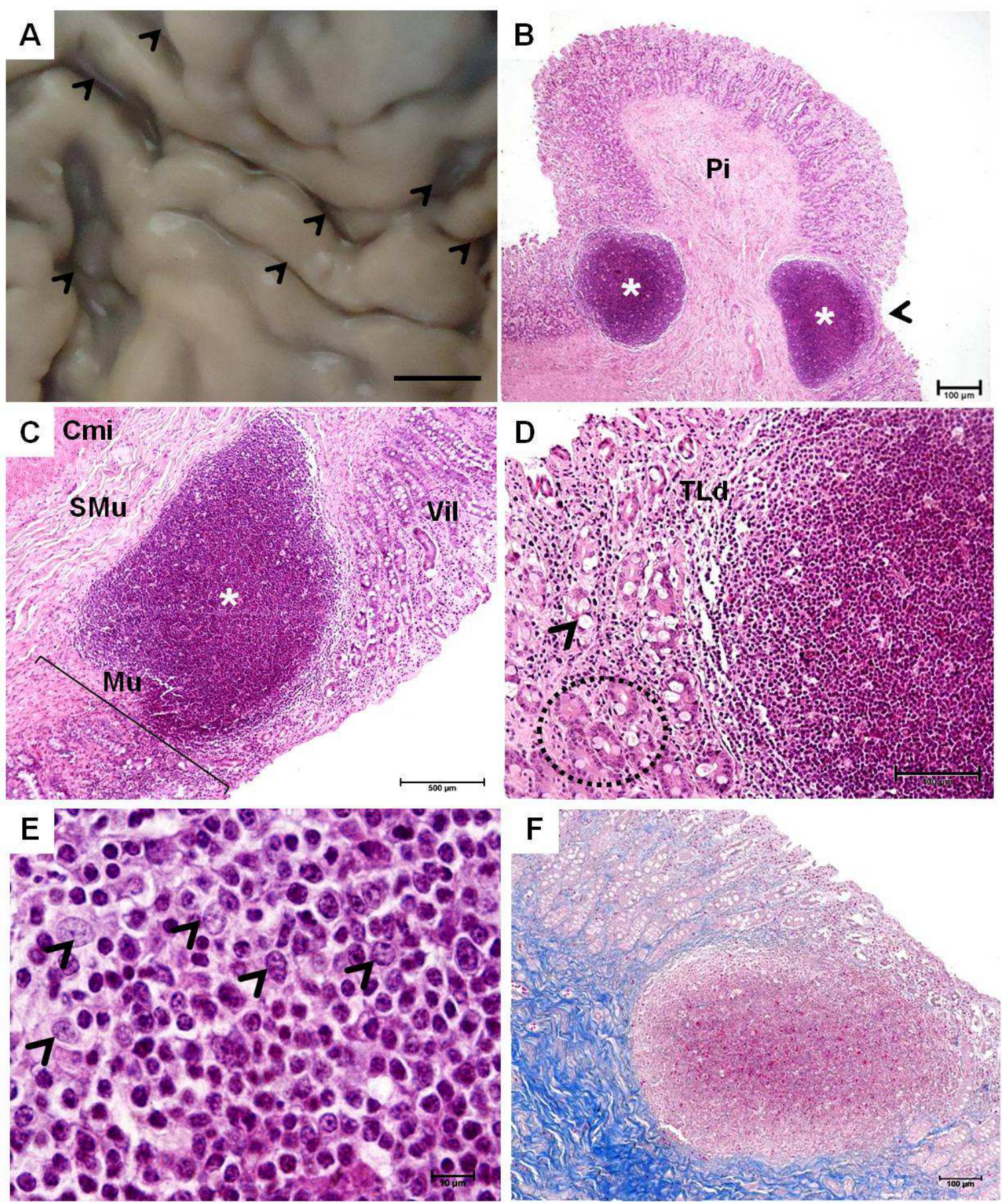

Fonte: (SILVA, F. M. O., 2014)

Legenda: Figura 4. A. Intestino de Sotalia fluviatilis. Mucosa interna, evidenciando a presença de aglomerados de tecido linfoide, formando dobras e sulcos, indicados por cabeças de seta. Barra: 0,5cm. B-D. Fotomicrografias de Placas de Peyer, porção proximal (B-D e F) e mediana (E) do intestino delgado de Inia geofrensis. B. Prega intestinal (Pi), com a presença de dois nódulos linfáticos isolados $\left({ }^{*}\right)$. Área com ausência de vilosidades na luz intestinal indicada por cabeça de seta. Hematoxilina-eosina (HE). 10x. C. Nódulo linfático $\left({ }^{*}\right)$ em maior aumento. Vilosidade (Vil), mucosa $(\mathrm{Mu})$, submucosa $(\mathrm{SMu})$ e camada muscular interna (Cmi). HE. 10x. D. Tecido linfático difuso (TLd) em comunicação com o lúmen intestinal. Destaque para as unidades secretoras (glândulas mucosas) das glândulas de Brünner. Célula caliciforme indicada por cabeça de seta. HE. 20x. E. Linfoblastos indicados por cabeça de seta, circundados por linfócitos de núcleo mais escuro e em menor tamanho. HE. 100x. F. Nódulo linfático $\left(^{*}\right)$ delimitado por fibras colágenas, com ausência de cápsula. Tricrômio de Masson. 10x. 
Figura 5 - Intestino grosso e tecidos linfoides associados à mucosa gastrointestinal em Odontocetos
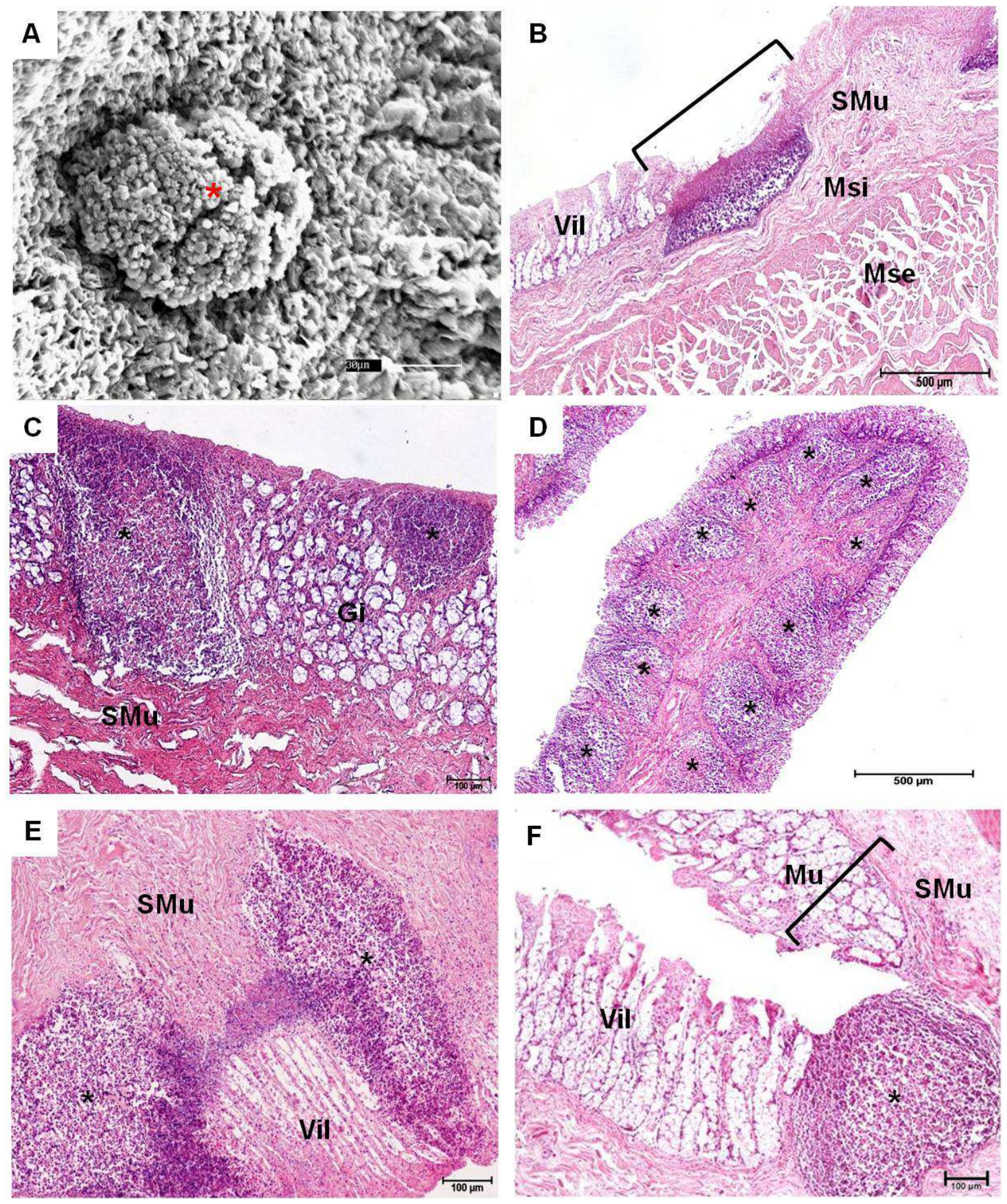

Fonte: (SILVA, F. M. O., 2014)

Legenda: Figura 5. Terço inicial (A, D), medial (C, E, F), distal (B). A. Peponocephala electra jovem. Nódulo linfático protuberante $\left(^{*}\right)$ após criofratura do fragmento de intestino grosso. B-F. Sotalia guianensis. B. Glândulas intestinais (Gi) em evidência, circundando o nódulo linfático ${ }^{*}{ }^{*}$. Camada submucosa (SMu). 20x. B. Transição do epitélio glandular (Vilosidade - Vil) e epitélio estratificado em destaque. Camada muscular interna (Msi) e externa (Mse) visíveis. 10x. C. Glândulas intestinais (Gi) em evidência, circundando os nódulos linfáticos $\left(^{*}\right)$. Camada Submucosa (SMu). HE. 20x. D. Nódulos linfáticos solitários, de tamanhos bem distintos. Hematoxilina-eosina (HE). 20x. E. Stenella clymene. Nódulos linfáticos com comunicação entre si ("ponte de tecido linfático difuso") indicada por cabeça de seta. Vilosidade (Vil) e camada submucosa (SMu). HE. 10x. F. Globicephala macrorhynchus jovem. Nódulo linfático $\left({ }^{*}\right)$ presente na fossa formada pelas pregas intestinais. Vilosidade (Vil), mucosa (Mu) e submucosa (SMu). HE. 10x. 


\subsubsection{Tonsila anal}

A tonsila anal (TA) foi composta por um agregado de tecido linfoide, mais discreto em tamanho quando comparada com a tonsila orofaríngea. Assim como a TO, a TA possui criptas e/ou fendas que ocorrem exclusivamente no canal anal (Figura 6A), se estendendo até o ânus.

Histologicamente, a tonsila anal foi composta por ramificações de epitélio escamoso que penetram na mucosa intestinal e dão origem as criptas. Aglomerados de linfócitos, difusos (Figura 6B) ou organizados (Figura 6C), recobrem algumas regiões das criptas, muitas vezes penetrando na lâmina própria (Figura 6B). Estes aglomerados podem se organizar em nódulos linfáticos (Figura 6D), que são delimitados por uma rede de fibras colágenas densamente organizadas (Figuras 6E e 6F). 
Figura 6 - Tonsila anal em Sotalia guianensis
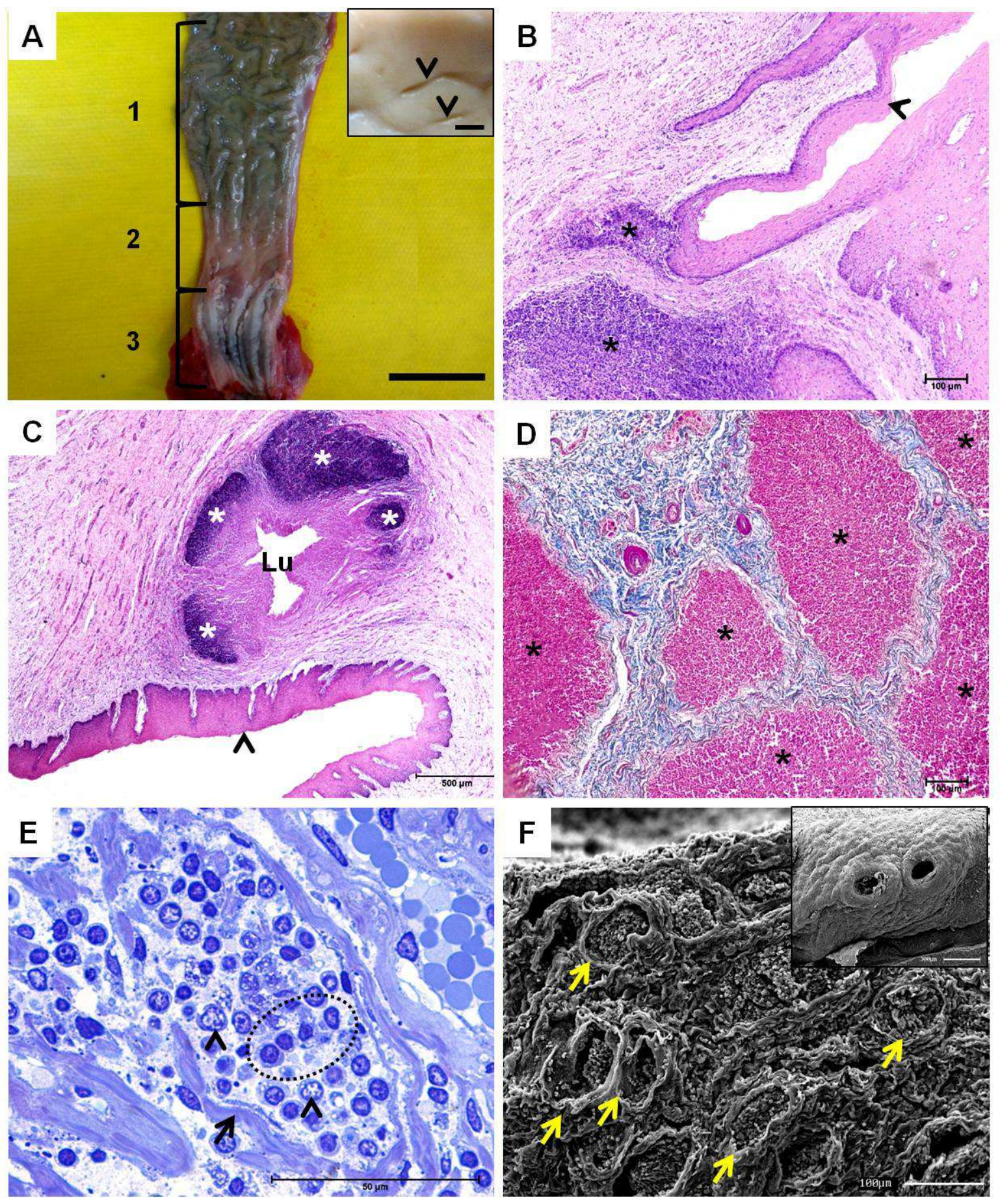

Fonte: (SILVA, F. M. O., 2014)

Legenda: Figura A. Segmento distal do intestino. 1. Mucosa pregueada contendo agregados linfoide; 2. Epitélio sem tecido linfoide; 3 . Canal anal. Barra: $2 \mathrm{~cm}$. Presença de fendas e criptas na área em maior aumento. Barra: 0,5cm. B-C. Cripta revestida por epitélio escamoso (cabeça de seta). Aglomerados de linfócitos $\left({ }^{*}\right)$ circundando o lúmen (Lu) da cripta. Hematoxilinaeosina. HE. B. 10x. C. 20x. D. Nódulos linfáticos $\left({ }^{*}\right)$ circundados por fibras colágenas, coradas em azul. Tricrômio de Masson. 10x. E. Nódulo linfático, delimitado por fibras colágenas densamente organizadas (seta). Presença de linfócitos (área em destaque) e linfoblastos (cabeça de seta). Corte semi-fino. Azul de Toluidina. 8.900x. F. Fotomicrografia eletrônica de varredura. Nódulos linfáticos, delimitados por fibra colágena, indicados por setas. Em maior aumento, abertura das criptas tonsilares. 


\section{DISCUSSÃO}

O sistema imune presente nas mucosas é o maior presente no corpo se considerarmos seu tamanho e função, uma vez que o tecido mucoso recobre grande parte dos tecidos do corpo de humanos e mamíferos terrestres e aquáticos. Assim, a produção de linfócitos nestes tecidos é essencial para a produção de uma resposta imune rápida e eficiente (SOCIETY OF MUCOSAL IMMUNOLOGY, 2012).

Apesar dos locais dos MALTs serem anatomicamente separados, eles permanecem ligados funcionalmente, uma vez que os linfócitos presentes em um local específico estimulam uma resposta imunológica generalizada, levando a produção de IgA na mucosa de inúmeros órgãos (CESTA, 2006). Assim, o sistema imune da mucosa produz uma resposta celular independente e uma resposta adquirida sistêmica (JANEWAY; MEDZHITOV, 2002).

Verificamos a presença de dois tipos específicos de estrutura MALT, uma organizada (O-MALT), delimitada por fibras colágenas organizadas, e uma desorganizada ou difusa (D-MALT), composta por populações de linfócitos entre a lâmina própria e a base do epitélio de revestimento.

As tonsilas orofaríngeas (TO) já foram descritas em espécimes como $T$. truncatus (CAVE, 1980; COWAN; SMITH, 1999) e Delphinapterus leucas (ROMANO et al., 1993). Em nosso estudo, as TOs foram encontradas nas espécies Sotalia guianensis, S. fluviatilis, Stenella clymene e Peponocephala electra, não sendo possível afirmar a não existência nas outras espécies Tal fato pode estar associado ao fato dessa estrutura não ser muito conhecidas pelos pesquisadores que trabalham na área e à sua localização incomum. Assim, mais estudos fazem-se necessários para verificar se as mesmas estão presentes em outras espécies ou se há alguma correlação entre espécies que justifique a ocorrência ou ausência desta tonsila.

Smith, Turnbull e Cowan (1999) acreditam que a localização da TO expõe os cetáceos a um perigo eminente em casos de infecções ou inflamações devido a sua localização nas vias respiratórias de cetáceos. No entanto, ao estudar T. truncatus, esses pesquisadores não encontraram nenhuma alteração significativa que ocluísse as vias aéreas dos animais avaliados, sugerindo que a resposta imune deste órgão linfoide está de alguma forma segregada dos linfonodos presentes na região. Tal 
fato é corroborado no presente estudo, onde não houve aumento de tamanho em nenhum dos animais estudados.

A função adaptativa desta estrutura em cetáceos permanece incerta para muitos pesquisadores. De acordo com nossos achados histológicos, acreditamos que as TO podem ser comparadas com as tonsilas faríngeas em humanos e tonsilas palatinas em mamíferos terrestres, umas vez que apresentam as mesmas características linfoides (GRIST, 1990). Verificamos ainda presença de uma estrutura de superfície irregular, repletas de criptas e fendas, o que sugere uma barreira física para possibilitar a apreensão de corpos estranhos.

A pele possui um conjunto de mecanismos imunológicos únicos uma vez que está sob constante estresse fisioquímico. Streilein (1989) propõe que o sistema linfoide associado à pele (SALT) é composto uma coleção única de células que se organizam de acordo com a necessidade de proteger o animal contra patógenos. Em nosso estudo foram encontrados linfócitos maduros em fragmentos de pele em todos os animais analisados, de forma desorganizada ou não, o que corrobora com o descrito por Streilein (1983).

Os nódulos linfáticos presentes na cérvix uterina não possuem descrição semelhante em nenhuma literatura de cetáceos, já tendo sido relatado em humanos. Entretanto, este tipo de tecido linfoide associados na mucosa normalmente encontra-se presente em locais cujo contato com antígenos é constante (BANKS, 1998). Wira et al. (2005) acreditam que sua presença esteja intimamente ligada à migração celular, ativada pelas variações hormonais presentes durante o ciclo menstrual. Lima e Alves (2008) afirmam que a cérvix seria o principal sítio para uma resposta imune uma vez que nesta região há grande concentração de linfócitos intraepiteliais com potencial para ativação. Tal fato corrobora com os achados do presente estudo, uma vez que a fêmea que apresentava a MALT em sua cérvix estava em maturidade sexual.

Assim como a pele, o intestino é um local constantemente desafiado por antígenos durante toda a vida do animal, tornando-o altamente vulnerável a infecções (MACDONALD, 2003; HOORWEG; CUPEDO, 2008). A integridade desta mucosa é mantida por inúmeras células de defesa, que podem estar organizadas estruturalmente ou não. Em cetáceos, Cowan et al. (1999) descreveram a presença de uma placa contínua de tecido linfoide na lâmina própria da mucosa e submucosa do intestino de $T$. truncatus jovens. $O$ mesmo foi verificado em nosso estudo, com a 
presença de placas contínuas e descontinuas nas porções proximal e medial dos intestinos avaliados.

As tonsilas anais (TA) foram observadas em inúmeras espécies de cetáceos, tais como Physeter catodon (UYS; BEST, 1966), Eschrichtius robustus (COWAN; BROWNELL, 1974), Platanista gangetica (YAMASAKI; KOMATSU; KAMIJA, 1977), Stenella coeruleoalba (KOMATSU, 1979) e T. truncatus (COWAN; SMITH, 1995). No entanto, estudos desenvolvidos por Cave (1980), Yamasaki, Takahashi e Kamija (1975) e Yamasaki, Komatsu e Kamija (1977) e Romano et al. (1993) não relatam a ocorrência da TA nas espécies avaliadas, diferente deste estudo onde estas tonsila foram encontradas em quatro das sete espécies estudadas.

Não podemos afirmar que esta estrutura é universal em cetáceos, uma vez que os relatos variam entre as espécies. Acreditamos que a TA ocorra em maior número do que o verificado na literatura, fato inerente à dificuldade de identificação das mesmas durante o exame macro e microscópico do intestino, já que a observação de sua presença ou ausência só é possível através da abertura e avaliação de toda a porção distal do intestino.

Cowan et al. (1999) acreditam que as TAs são consideradas de extrema importância imunológica em cetáceos devido à sua localização em um ponto anatômico estratégico, funcionando como barreira à apresentação de antígenos em casos de refluxo durante o mergulho (BEINEKE et al., 2010). Tal fato é corroborado em nosso estudo, uma vez que linfócitos $T$, células base para apresentação de antígeno, encontravam-se presentes nas TAs avaliadas no presente estudo.

A marcação positiva dos linfócitos T CD3 observada neste estudo, utilizando um anticorpo anti-rat específico para humanos e que possuem reatividade cruzada com $P$. phocoena, corrobora com o verificado por Beineke et al. (2001), que utilizou um anticorpo anti-rabbit. Tais achados mostram que é possível utilizar antígenos para leucócitos de diferentes espécies para determinação do fenótipo de linfócitos em tecidos linfoides de cetáceos.

Diante destes achados, podemos concluir que o tecido linfoide associado à mucosa em cetáceos é semelhante ao observado em mamíferos terrestre, com adaptações inerentes ao meio aquático, como a presença de tonsilas orofaríngea e anal, assegurando uma resposta imunológica mais eficiente diante de desafios antigênicos constantes, tais como contaminantes ambientais, presentes em seu habitat. 


\section{CONCLUSÕES}

Com base no presente estudo e na bibliografia existente, podemos concluir que os órgãos e tecidos linfoides em cetáceos são semelhantes aos observados em mamíferos domésticos, com algumas particularidades, consideradas adaptativas ao meio aquático.

Novos grupos de linfonodos foram descritos para os cetáceos de ocorrência no litoral brasileiro, possuindo arquitetura semelhante ao descrito na literatura para mamíferos terrestres.

Baços acessórios, de morfologia idêntica ao baço principal, podem tem uma função de reservatório sanguíneo complementar, assim podendo ser considerado como um órgão linfoide compensatório à atividade esplênica durante o mergulho.

O timo, assim como em mamíferos terrestres, possui involução e presença de corpúsculos de Hassal maiores relacionadas com a idade.

Os tecidos linfoides associados à mucosa em cetáceos são semelhantes ao observado em mamíferos terrestre, com adaptações inerentes ao meio aquático, como a presença de tonsilas orofaríngea e anal, assegurando uma resposta imunológica mais eficiente diante de desafios antigênicos constantes presentes em seu habitat.

Através dos dados obtidos neste estudo será possível uma melhor compreensão do funcionamento e estrutura do sistema imunológico das espécies estudadas, colaborando na elucidação das causas de encalhe destes animais, que poderão funcionar como potenciais indicadores ambientais. 


\section{REFERÊNCIAS}

ABBAS, A. K.; LICHTMAN, A. H.; POBER, J. S. Imunologia celular e molecular. Rio de Janeiro: Campus, 2012. 570 p.

ALAM, R.; GORSKA, M. Lymphocytes, Journal of Allergy and Clinical Immunology, v. 111, n. 2, p. S476-S485, 2003.

ANDERSON, J. Anatomical and zoological researches: comprising an account of the two expeditions to western Yunnan in 1869 and 1875; and a monograph of the two cetacean genera, Platanista and Orcella. London: Bernard Quaritch, 1878.

ANTHONY R.; COUPIN F. Recherches anatomiques sur le vestibule de l'appareil respiratoire: (Poche gutturale-Hyoïde-Larynx) du Mesoplodon. Madrid: Memorias del Instituto Espanõl de Oceanografía, 1930. Mem XIV 9-11.

BABAYAN, S. A.; ALLEN, J. E.; BRADLEY, J. E.; GEUKING, M. B.; GRAHAM, A. L.; GRENCIS, R. K.; KAUFMAN, J.; MCCOY, K. D.; PATERSON, S.; SMITH, K. G.; TURNBAUGH, P. J.; VINEY, M. E.; MAIZELS, R. M.; PEDERSEN, A. B. Wild immunology: converging on the real world. Annals of the New York Academy of Sciences, v. 1236, p. 17-29, 2011.

BACHA, W. J.; BACHA, L. M. Color atlas of veterinary histology. Philadelphia: Lippincott Williams \& Wilkins, 2000. 336 p.

BANKS, W. J. Histologia veterinária aplicada. 2. ed. São Paulo: Manole, 1998. $630 \mathrm{p}$.

BEDDARD, F. E. Notes upon the anatomy of a manatee (Trichechus inunguis) lately living in the Society's gardens. Proceedings of the Zoological Society of London, p. 47-53, 1897.

BEHRMANN G. Morphology and histology of the laryngeal sac of toothed whales. Aquatic Mammals, v. 13, p. 119-121, 1987.

BEINEKE, A.; SIEBERT, U.; BAUMGARTNER, W. The immune system of marine mammals. Part 2: Morphology, immunophenotyping and pathology of lymphoid organs. Tierarztl Prax Ausg K Klientiere Heimtiere, v. 34, p. 201-207, 2006.

BEINEKE, A.; SIEBERT, U.; MCLACHLAN, M.; BRUHN, R.; THRON, K.; FAILING, K.; MÜLLER, G.; BAUMGÄRTNER, W. Investigations of the potential influence of environmental contaminants on the thymus and spleen of harbor porpoises

(Phocoena phocoena). Environmental Science \& Technology Letters, v. 39, n. 11, p. 3933-3938, 2005.

BEINEKE, A.; SIEBERT, U.; WOHLSEIN, P.; BAUMGÄRTNER, W. Immunology of whales and dolphins. Veterinary Immunology and Immunopathology, v. 15, n. 133, p. 81-94, 2010. 
BEINEKE, A.; SIEBERT, U.; WÜNSCHMANN, A.; STOTT, J. L.; PRENGEL, I.; KREMMER, E.; BAUMGÄRTNER, W. Immunohistochemical investigation of the cross-reactivity of selected cell markers from various species for characterization of lymphatic tissues in the Harbour porpoise (Phocoena phocoena). Journal of Comparative Pathology, v. 125, n. 4, p. 311-317, 2001.

BERTA, A.; SUMICH, J. L. Marine mammals: evolutionary biology. California: Academic Press, 1999. 560 p.

BOSSART, G. D.; REIDARSON, T. H.; DIERAUF, L. A.; DUFFIELD, D. A. Clinical pathology. In: DIERAUF, L. A. CRC handbook of marine mammal medicine: health, disease and rehabilitation. Boca Raton: CRC Press, 2001. p. 383-436.

BRYDEN, M. M. Growth and development of marine mammals. In: HARRISON, R. J. Functional anatomy of marine mammals. New York: Academic Press, 1972. p. 179.

BRYDER, D.; SIGVARDSSON, M. Shaping up a lineage-lessons from B lymphopoesis. Current Opinion in Immunology, v. 22, n. 2, p. 148-53, 2010.

CARVALHO, V. L.; MOTTA, M. R.; NUNES-PINHEIRO, D. C. S.; NOGUEIRA, T. N. A. G.; CAMPELLO, C. C. Ocorrência de baços acessórios em boto-cinza (Sotalia guianensis) - aspectos histológicos. Acta Scientiae Veterinariae, v. 37, n. 2, p. 77180, 2009.

CAVAGNOLO, R. Z. The immunology of marine mammals. Developmental and Comparative Immunology, v. 3, p. 245-257, 1979.

CAVE, A. J. E. Note on Tursiops visceral histology. In: PILLERI, G. Investigations on cetacea. $11^{\text {th }}$ ed. Switzerland: 'Der Bund', 1980. p. 11-113.

CESTA, M. F. Normal structure, function, and histology of mucosa-associated lymphoid tissue. Toxicological Pathology, v. 34, n. 5, p. 599-608, 2006

CHINN, I. K.; BLACKBURN, C. C.; MANLEY, N. R.; SEMPOWSKI, G. D. Changes in primary lymphoid organs with aging. Seminars in Immunology, v. 24, n. 5, p. 309-320, 2012.

CLARK, L. S.; TURNER, J. P.; COWAN, D. F. Involution of lymphoid organs in bottlenose dolphins (Tursiops truncatus) from the Western Gulf of Mexico: implications for life in an aquatic environment. The Anatomical Record. Part A, Discoveries in Molecular, Cellular, and Evolutionary Biology, v. 282, n. 1, p. 6773, 2005.

COOPER, M. D. A life of adventure in immunobiology. Annual Reviews in Immunology, v. 28, p. 1-19, 2010.

COWAN, D. F. Involution and cystic transformation of the thymus in the bottlenose dolphin, Tursiops truncatus. Veterinary Pathology, v. 31, p. 648-653, 1994. 
COWAN, D. F.; BROWNELL, JR, R. L. Gut associated lymphoepithelial organ ("anal tonsil") in the gray whale. In: HARRISON, R. J. Functional Anatomy of Marine Mammals. Vol. 2. New York: Academic Press, 1974. v.2, p. 321-332.

COWAN, D. F.; SMITH, T. L. Morphology of complex lymphoepithelial organs of the anal canal ('anal tonsil') in the bottlenose dolphin, Tursiops truncatus. Journal of Morphology, v. 223, p. 263-268, 1995.

COWAN, D. F.; SMITH, T. L. Morphology of the lymphoid organs of the bottlenose dolphin, Tursiops truncatus. Journal of Anatomy, v. 194, p. 505-517, 1999.

CUBAS, Z. S.; SILVA, J. C. R.; CATÃO-DIAS, J. L. Tratado de animais selvagens. Medicina veterinária. São Paulo: Roca, 2007. 1354 p.

CUNNINGHAM, J. G.; KLEIN, B. G. Tratado de fisiologia veterinária. Rio de Janeiro: Guanabara Koogan, 2008. 852 p.

DELVES, P. J.; MARTIN, S. J.; BURTON, D. H.; ROITT, I. M. Roitt - Fundamentos de imunologia. Rio de Janeiro: Guanabara Koogan, 2013. 568 p.

DYCE, K. M.; SACK, W. O.; WENSING, C. J. G. Tratado de anatomia veterinária. Rio de Janeiro: Editora Elsevier, 2010. 856p.

ERGUN, A.; DORAN. G.; COSTELLO, J. C.; PAIK, H. H.; COLLINS, J. J.; MATHIS, D.; BENOIST, C.; ImmGen CONSORTIUM. Differential splicing across immune system lineages. Proceedings of the National Academy of Sciences of the United States of America, v. 110, n. 35, p. 14324-14329, 2013.

EROSCHENKO, V. P. Di Fiore's atlas of histology with functional correlations. Philadelphia: Lippincott Williams \& Wilkins, 2008. 552 p.

GASPER, P. W. Hematopoiesis. In: FELDMAN, B. F.; ZINKL, J. G.; JAIN, N. C. Schalm's veterinary hematology. Philadelphia: Lippincott Williams \& Wilkins, 2000. p. 61-102.

GERACI, J. R.; LOUNSBURY, V. J. Marine mammals ashore: a field guide for strandings. Baltimore: National Aquarium in Baltimore, 2005.

GREEN, R. F. Observations on the anatomy of some cetaceans and pinnipeds. In: RIDGWAY, S. H. Mammals of the sea: biology and medicine, Springfield: Charles C. Thomas, 1972. p. 247-295.

GRIST, W. J. The Tonsils and pharynx. In: WALKER, H. K.; HALL, W. D.; HURST, J. W. Clinical methods: the history, physical and laboratory examinations. Boston:

Butterworths, 1990. p. 626-627.

HARRISON, R. J. Functional anatomy of marine mammals. London: Academic Press, 1974. 366 p. 
HARVEY, J. W. Hematopoiesis. In: Veterinary Hematology: a diagnostic guide and color atlas. Missouri: Elsevier Saunders, 2012. p. 33-48.

HELLINGS, P.; JORISSEN, M.; CEUPPENS, J. L. The Waldeyer's ring. Acta Otorhino-Laryngologica Belgica, v. 54, n. 3, p. 237-41, 2000.

HOORWEG, K.; CUPEDO, T. Development of human lymph nodes and Peyer's patches. Seminars in Immunology, v. 20, p. 164-170. 2008.

HYTTEL, P. Desenvolvimento das células do sangue, do coração e do sistema vascular. In: HYTTEL, P.; SINOWATZ, F.; VEJLSTED, M. Embriologia Veterinária. Rio de Janeiro: Elsevier, 2012. p. 182-207

IBAMA. Mamíferos aquáticos do Brasil: Plano de ação, versão II. Brasília: Instituto Brasileiro do Meio Ambiente e dos Recursos Naturais Renováveis, 2001. 96 p.

IUCN. The IUCN red list of threatened species. Disponível em: <http://www.iucnredlist.org >. Acesso em: 02 mai. 2014.

IWASAKI, A.; MEDZHITOV, R. Regulation of adaptive immunity by the innate immune system. Science, v. 327, n. 5963, p. 291-295, 2010.

JAGANNATHAN-BOGDAN, M.; ZON, L. I. Hematopoiesis. Development, v. 140, p. 2463-2467, 2013.

JANEWAY, C. A. JR; MEDZHITOV, R. Innate immune recognition. Annual Review of Immunology, v. 20, p. 197-216, 2002.

JANEWAY, C. A; TRAVES, P.; WALPORT, M.; SHLOMCHIK, M. Imunobiologia. 0 sistema imune na saúde e na doença. Porto Alegre: Artmed, 2006.

JEFFERSON, T. A.; LEATHERWOOD, S.; WEBBER, M. A. FAO Species Identification Guide. Marine Mammals of the World. Rome: FAO. 1993.

JEPSON, P. D.; BENNETT, P. M.; ALLCHIN, C. R.; LAW, R. J.; KUIKEN, T.; BAKER, J. R.; ROGAN, E.; KIRKWOOD, J. K. Investigating potential associations between chronic exposure to polychlorinated biphenyls and infectious disease mortality in harbor porpoises from England and Wales. The Science of the Total Environment, v. 243-244, p. 339-348, 1999.

JONES, T. C.; HUNT, R. D.; KING, N. W. Patologia veterinária. São Paulo: Manole, 2000. $1415 \mathrm{p}$.

KOMATSU, S. The anal tonsil in the striped dolphin Stenella coeruleoalba. Journal Of Liberal Arts \& Sciences Sapporo Medical College, v. 20, p. 53-55, 1979.

KONIG, H. E.; LIEBICH, H. G. Anatomia dos animais domésticos. Porto Alegre, Artmend, 2011.788 p. 
KOZUKA, Y.; NASU, T.; MURAKAMI, T.; YASUDA, M. Comparative studies on the secondary lymphoid tissue areas in the chicken bursa of Fabricius and calf ileal Peyer's patch. Veterinary Immunology and Immunopathology, v. 133, n. 2-4, p. 190-197, 2010.

LAI, A.; KONDO, M. T and B lymphocyte differentiation from hematopoietic stem cell. Seminars in Immunology. v. 20, n. 4, p. 207-212, 2008.

LIANG, H. C.; HOLMES, R.; ZÚÑIGA-PFLÜCKER, J. C. Directed differentiation of embryonic stem cells to the T-lymphocyte lineage. Methods in Molecular Biology, v. 1029 , p. 119-128, 2013.

LIMA, Y. A. R.; ALVES, M. F. C. O sistema imune da mucosa do trato genital feminino e o impacto das doenças sexualmente transmissíveis. Revista de Patologia Tropical, v. 37, n. 4, p. 295-309, 2008.

LOWDEN, S.; HEATH, T. Segmented filamentous bacteria associated with lymphoid tissues in the ileum of horses. Research in Veterinary Science, v. 59, n. 3, p. 272274, 1995.

LUBIS, I.; LADDS, P. W.; REILLY, L. R. Age associated morphological changes in the lymphoid system of tropical cattle. Research in Veterinary Science, v. 32, p. 270-277, 1982.

MARCONDES, M. C. Odontocetos. In: REMANE. Protocolo de conduta para encalhes de mamíferos aquáticos. Recife: IBAMA, 2005. p. 166-184.

MACDONALD, T. T. The mucosal immune system. Parasite Immunology, v. 25, p. 235-246, 2003.

MERCHANT, H. A.; MCCONNELL, E. L.; LIU, F.; RAMASWAMY, C.; KULKARNI, R. P.; BASIT, A. W.; MURDAN, S. Assessment of gastrointestinal $\mathrm{pH}$, fluid, fluid and lymphoid tissue in the guinea pig, rabbit and pig, and implications for their use in drug development. European Journal of Pharmaceutical Sciences: Official Journal of the European Federation for Pharmaceutical Sciences, v. 42, n. 1-2, p. 3-10, 2011.

MITCHELL, R. N.; KUMAR, V.; ABBAS, A. K.; FAUSTO, N. Robbins \& Cotran. Fundamentos de patologia. Rio de Janeiro: Elsevier, 2012. 712 p.

NAGY, N.; OLÁH, I. Pyloric tonsil as a novel gut-associated lymphoepithelial organ of the chicken. Journal of Anatomy, v. 211, p. 407-411, 2007.

OWEN, J. J.; RAFF, M. C. Studies on the differentiation of thymus-derived lymphocytes. The Journal of Experimental Medicine, v. 132, n. 6, p. 1216-1232, 1970.

PARHAM, P. The immune system. New York: Garland Science, 2009. 608p.

PARENTE, C. Interações entre cetáceos e aquisições sísmicas marítimas no Brasil. 2008. 83 f. Tese (Doutorado em Oceanografia) - Faculdade de Oceanografia, Universidade Federal de Pernambuco, Recife, 2008. 
PABST, D. A.; ROMMEL, S. A.; MCLELLAN, W. A. Functional anatomy of marine mammals. In: REYNOLDS, J. E.; ROMMEL, S. A. Biology of marine mammals. Smithsonian Institution Press: Washington, 1999. p. 15-72.

PASTORET, P. P.; GRIEBEL, P.; BAZIN, H.; GOVAERTS, A. Handbook of vertebrate immunology. San Diego: Academic, 1998. $673 \mathrm{p}$.

PILLERI, G.; ARVY, L. Aselli's pseudopancreas (nodi lymphatici mesenterici) in two delphinids: Delphinus delphis and Stenella coeruleoalba. In: PILLERI, G.

Investigations on cetacea, $3^{\text {rd }}$ ed. Switzerland: 'Der Bund', 1971. p. 189-193.

PINEDO, M. C.; ROSAS, F. C. W.; MARMONTEL, M. Cetáceos e pinípedes do Brasil: uma revisão dos registros e guia para identificação das espécies. Manaus: UNEP/FUA, 1992. 213 p.

PRESS, C. MCL.; LANDSVERK, T. Immune system. In: EURELL, J. A.; FRAPPIER, B. L. Dellmann's textbook of veterinary histology. Ames: Blackwell Publishing, 2012. p. 134-152.

RAMÍREZ, J.; LUKIN, K.; HAGMAN, J. From hematopoietic progenitors to B cells: mechanisms of lineage restriction and commitment. Current Opinion in Immunology, v. 22, n. 2, p. 177-84, 2010.

RAMISCAL, R. R.; VINUESA, C. G. T-cell subsets in the germinal center. Immunological Reviews, v. 252, n. 1, p. 146-155, 2013.

REDECKE, V.; WU, R.; ZHOU, J.; FINKELSTEIN, D.; CHATURVEDI, V.; HIGH A. A.; HÄCKER, H. Hematopoietic progenitor cell lines with myeloid and lymphoid potential. Nature Methods, v. 10, n. 8, p. 795-803, 2013.

REECE, W. O. Dukes - Fisiologia dos animais domésticos. Rio de Janeiro: Guanabara Koogan, 2006. 942 p.

REIDARSON, T. H.; DUFFIELD, D; McBAIN, J. Normal hematology of marine mammals. In: FELDMAN, B. F.; ZINKL, J. G.; JAIN, N. C. Schalm's veterinary hematology. $5^{\text {th }}$ ed. Philadelphia: Lippincott Williams \& Wilkins, 2000. p. 1164-1173.

REIDENBERG, J. S.; LAITMAN, J. T. Sisters of the sinuses: cetacean air sacs. Anatomical Record (Hoboken), v. 291, n. 11, p. 1389-1396, 2008.

REYNOLDS, J. E.; ROMMEL, S. A.; BOLEN, M. E. Anatomical dissection: thorax and abdomen. In: PERRIN, W. F.; WÜRSIG, B.; THEWISSEN, H. G. M. Encyclopedia of marine mammals. San Diego: Academic Press, 2002. p. 21-30.

ROLINK, A. G.; MASSA, S.; BALCIUNAITE, G.; CEREDIG, R. Early lymphocyte development in bone marrow and thymus. Swiss Medical Weekly, v. 136, n. 43-44, p. 679-683, 2006. 
ROMANO, T. A.; ABELLA, K.; COWAN, D.; CURRY, B. Investigation of the morphology and autonomic innervation of the lymphoid organs in the pantropical spotted, spinner, and common dolphins (Stenella attenuata, Stenella longirostris and Delphinus delphis) incidentally entangled and drowned in the tuna purse-seine fishery in the eastern tropical pacific. [s.I.]: La Jolla Administrative Report. Southwest Fisheries Science Center, National Marine Fisheries Service, 2002. 25 p.

ROMANO, T. A.; FELTEN, S. Y.; OLSCHOWKA, J. A.; FELTEN, D. L. A microscopic investigation of the lymphoid organs of the beluga, Delphinapterus leucas. Journal of Morphology, v. 215, n. 3, p. 261-87, 1993.

ROMMEL, S. A.; LOWENSTINE, L. J. Gross and microscopic anatomy. In:

DIERAUF, L. A. CRC handbook of marine mammal medicine: health, disease and rehabilitation. Boca Raton: CRC Press, 2001. p. 129-164.

ROTHKÖTTER, H. J. Anatomical particularities of the porcine immune system - a physician's view. Developmental Comparative Immunology, v. 33, n. 3, p. 267-72, 2009.

RUOPPOLO, V. Patologia comparada de cetáceos e pinípedes. 2003. $131 \mathrm{f}$. Dissertação (Mestrado em Patologia Veterinária) - Faculdade de Medicina Veterinária e Zootecnia, Universidade de São Paulo, São Paulo, 2003.

SHECHTER, R.; LONDON, A.; SCHWARTZ, M. Orchestrated leukocyte recruitment to immune-privileged sites: absolute barriers versus educational gates. Nature Reviews: Immunology, v. 13, n. 3, p. 206-218, 2013.

SIEBERT, U.; JOIRIS, C.; HOLSBEEK, L.; BENKE, H.; FAILING, K.; FRESE, K.; PETZINGER, E. Potential relation between mercury concentrations and necropsy findings in cetaceans from German waters of the North and Baltic Seas. Marine Pollution Bulletin, v. 38, p. 285-295. 1999.

SIGVARDSSON, M. Load and lock: the molecular mechanisms of B-lymphocyte commitment. Immunological Reviews, v. 238, n. 1, p. 47-62, 2010.

SILVA, F. M. O.; GUIMARÃES, J. P.; VERGARA-PARENTE, J. E.; CARVALHO, V. L.; MEIRELLES, A. C. O.; MARMONTEL, M.; FERRÃO, J. S. P.; MIGLINO, M. A. Morphological analysis of lymph nodes in Odontocetes from north and northeast coast of Brazil. Anatomical Record (Hoboken), v. 297, n. 5, p. 939-948, 2014a.

SILVA, F. M. O.; CARVALHO, V. L.; GUIMARÃES, J. P.; VERGARA-PARENTE, J. E.; MEIRELLES, A. C. O.; MARMONTEL, M.; MIGLINO, M. A. Accessory spleen in cetaceans and its relevance as a secondary lymphoid organ. Zoomorphology, v. 133, p. 343-350, 2014b.

SIMPSON, J. G.; GARDNER, M. B. Comparative microscopic anatomy of selected marine mammals. In: RIDGWAY, S. H. Mammals of the sea. Biology and medicine. Springfield: Charles C. Thomas, 1972. p. 298-418. 
SISSON, S.; GROSSMAN, J. D. Anatomia dos animais domésticos. Rio de Janeiro: Guanabara Koogan, 1981. v. 1-2, 3134 p.

SLIJPER, E. J. Organ weights and symmetry problems in porpoises and seals. Archives Neerlandaises de Zoologie, v. 13, p. 97-113, 1958.

SMITH, T. L.; TURNBULL, B. S.; COWAN, D. F. Morphology of the complex laryngeal gland in the atlantic bottlenose dolphin, Tursiops truncatus. The Anatomical Record, v. 254, p. 98-106, 1999.

SMITH-GARVIN, J. E.; SIGAL, L. J. Immunology: memory cells sound the alarm. Nature, v. 497, n. 7448, p. 194-196, 2013.

SOCIETY OF MUCOSAL IMMUNOLOGY. Principles of mucosal immunology. New York: Garland Science, 2012. 512 p.

SONI, J.; BAIRD, A. W.; O'BRIEN, L. M.; MCELROY, M.; CALLANAN, J. J.; BASSETT, H. F.; CAMPION, D.; BRAYDEN, D. J. Rat, ovine and bovine Peyer's patches mounted in horizontal diffusion chambers display sampling function. Journal of Controlled Release: Official Journal of the Controlled Release Society, v. 115, n. 1, p. 68-77, 2006.

STEVENS, S. K.; WEISSMAN, I. L.; BUTCHER, E. C. Differences in the migration of $B$ and T lymphocytes: organ-selective localization in vivo and the role of lymphocyteendothelial cell recognition. Journal of Immunology, v. 128, n. 2, p. 844-851, 1982.

STREILEIN, J. W. Skin-associated lymphoid tissue. Immunology series. v. 46, p. 73-96, 1989.

STREILEIN, J. W. Skin-associated lymphoid tissues (SALT): origins and functions. The Journal of Investigative Dermatology, v. 80, p. 12s-16s, 1983. Suppl.

TITTEL, K. Anatomia descritiva e funcional do corpo humano. São Paulo: Santos, 2006.

TIZARD, I. R. Veterinary immunology. Saint Louis: Saunders, 2012.

TSCHANZ, S. A.; BURRI, P. H.; WEIBEL, E. R. A simple tool for stereological assessment of digital images: the STEPanizer. Journal of Microscopy, v. 243, p. 47-59, 2011.

VEJLSTED, M. Desenvolvimento do sistema imune. In: HYTTEL, P.; SINOWATZ, F.; VEJLSTED, M. Embriologia veterinária. Rio de Janeiro: Elsevier, 2012. p. 208-215.

VUKOVIC, S.; LUCIC H.; GOMERCIC, H.; DURAS GOMERCIC, M.; GOMERCIC, T.; SKRTIC, D.; CURKOVIC, S. Morphology of the lymph nodes in bottlenose dolphin (Tursiops truncatus) and striped dolphin (Stenella coeruleoalba) from the Adriatic Sea. Acta Veterinara Hungatica, v. 53, n. 1, p. 1-11, 2005. 
UYS, C. J.; BEST, P. B. Pathology of lesions observed in whales flensed at Saldanha Bay, South Africa. Journal of Comparative Pathology, v. 76, p. 407-412, 1966.

WIRA, C. R.; FAHEY, J. V.; SENTMAN, C. L.; PIOLI, P. A.; SHEN, L. Innate and adaptive immunity in female genital tract: cellular responses and interactions. Immunological Reviews, v. 206, p. 306-335, 2005.

WÜNSCHMANN, A.; SIEBERT, U.; FRESE, K. Thymic cysts in harbor porpoises (Phocoena phocoena) from the German North Sea, Baltic Sea, and waters of Greenland. Veterinary Pathology, v. 36, n. 5, p. 391-396, 1999.

YAMASAKI, F.; KOMATSU, S.; KAMIYA, T. A. Comparative morphology of anal tonsils in Platanistidae. Scientific Reports of the Whales Research Institute, v. 29, p. 95-100, 1977.

YAMASAKI, F.; TAKAHASHI, K.; KAMIYA, T. Digestive tract of La Plata dolphin, Pontoporia blainvillei. II. Small and large intestines. Okajimas Folia Anatomica Japonica, v. 52, p. 1-26, 1975.

YE, M.; GRAF, T. Early decisions in lymphoid development. Current Opinion in Immunology, v. 19, n. 2, p. 123-128, 2007.

ZANDI, S.; BRYDER, D.; LEBIEN, T. W.; TEDDER, T. F. B lymphocytes: how they develop and function. Blood, v. 112, n. 5, p. 1570-1580, 2008.

ZWILLENBERG, H. H. L. Die mikroskopische anatomie der milz der furchenwale. Archives Neerlandaises de Zoologie, v. 13, p. 595-597, 1960. 


\section{ANEXO A - Licença Sisbio para atividades com finalidade científica}

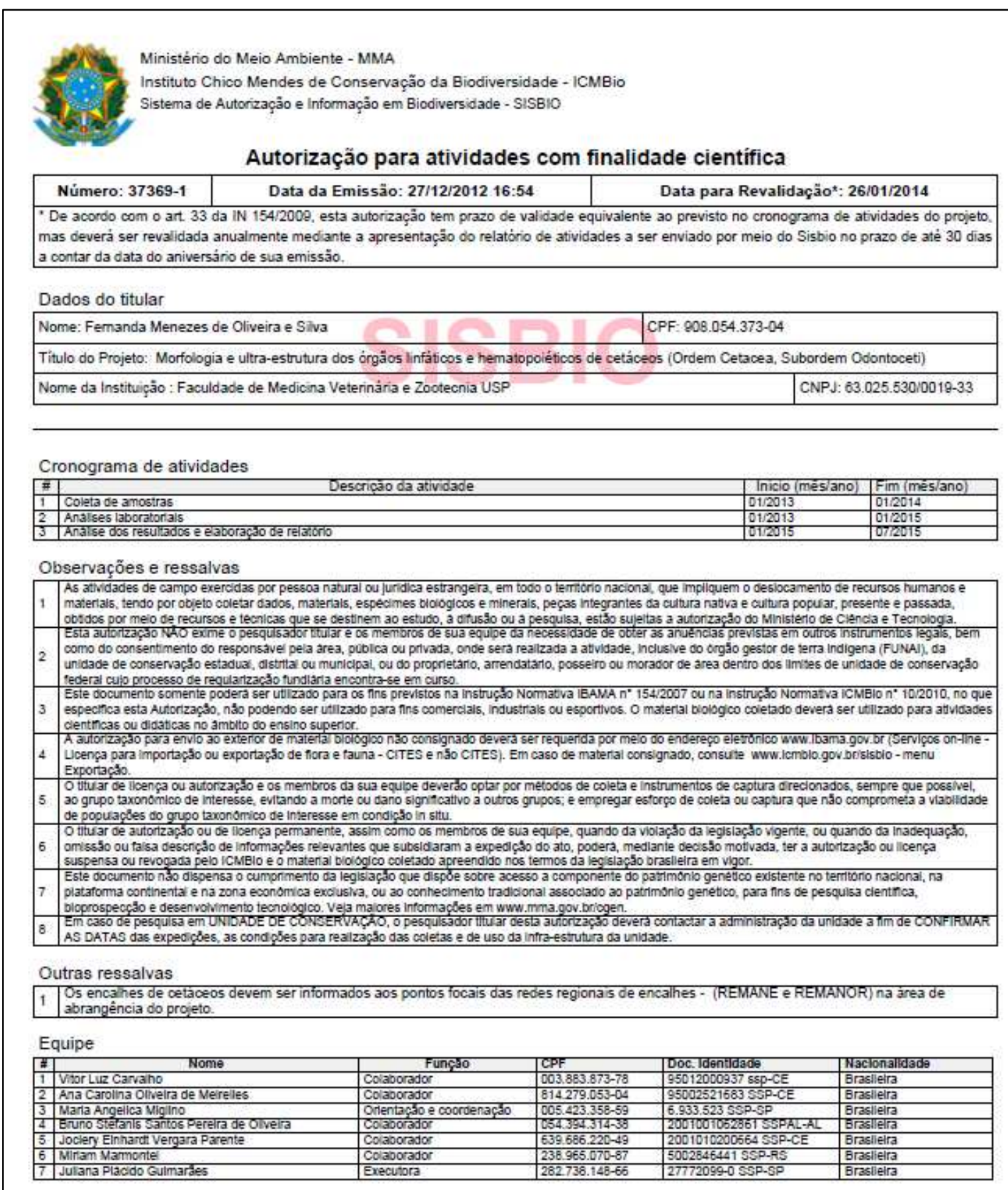

Este documento (Autorizaçäo para atividades com finalidade cientifica) foi expedido com base na instrução Nomativa $n^{\circ} 154 / 2007$. Através do código de autenticaçáo abaixo, qualquer cidadăo poderá verificar a autenticidade ou regularidade deste documento, por meio da página do SisbioncMBio na Internet (www.icmbio.gov.brisisbio).

Código de autenticação: 75729651 


\section{ANEXO B - Licença Sisbio para atividades com finalidade científica}

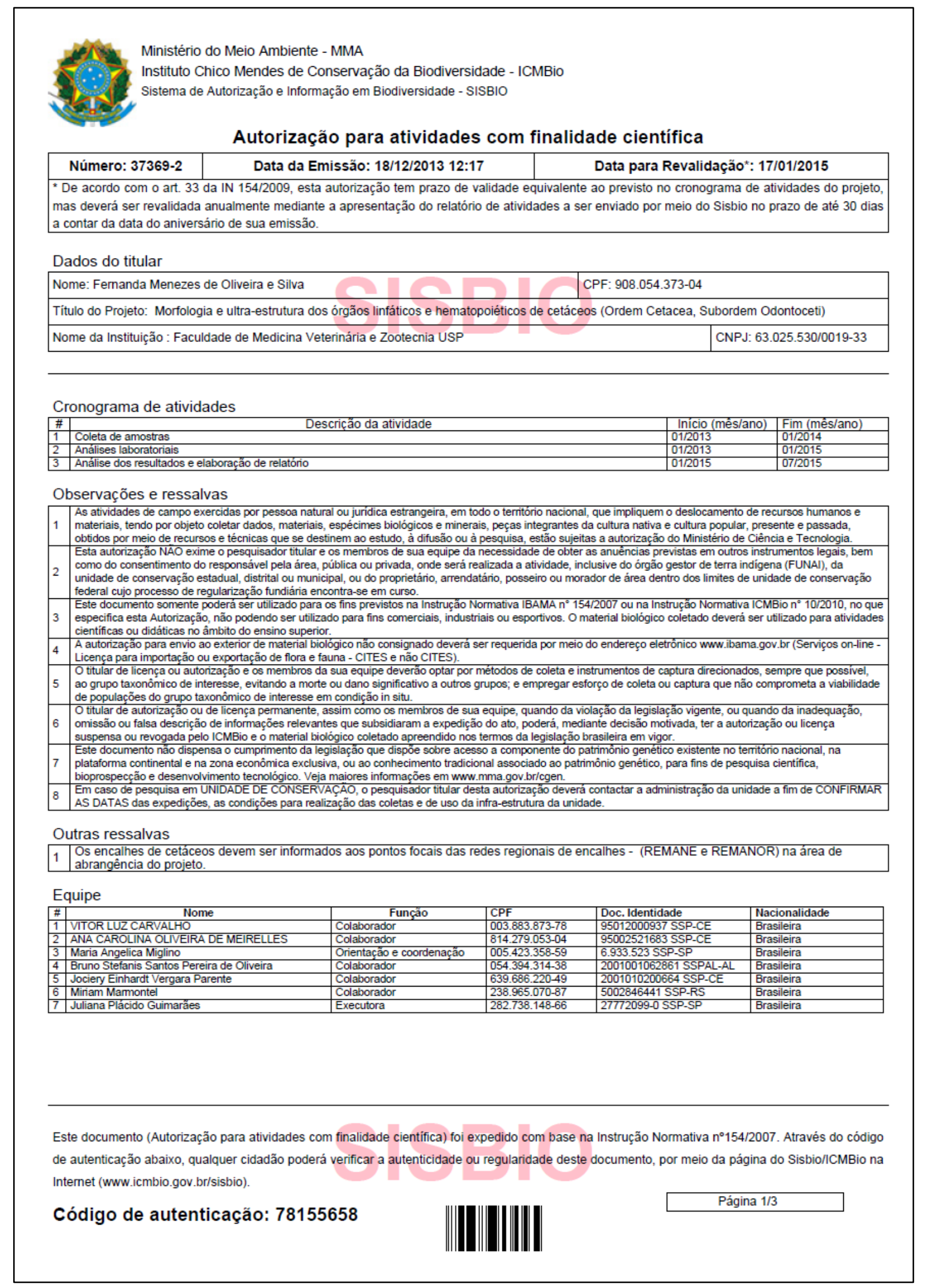




\title{
Morphological Analysis of Lymph Nodes in Odontocetes From North and Northeast Coast of Brazil
}

\author{
FERNANDA MENEZES DE OLIVEIRA E SILVA, ${ }^{1,2 *}$ \\ JULIANA PLÁCIDO GUIMARÃES, ${ }^{1,2}$ \\ JOCIERY EINHARDT VERGARA-PARENTE, ${ }^{2}$ VITOR LUZ CARVALHO, ${ }^{3}$ \\ ANA CAROLINA OLIVEIRA DE MEIRELLES, ${ }^{3}$ MIRIAM MARMONTEL, ${ }^{4}$ \\ JULIANA SHIMARA PIRES FERRÃO,${ }^{1}$ AND MARIA ANGELICA MIGLINO ${ }^{1}$ \\ ${ }^{1}$ Department of Surgery, School of Veterinary Medicine and Animal Science, University of \\ Sao Paulo (FMVZ/USP), Av. Prof. Dr. Orlando Marques de Paiva, 87, Cidade Universitária, \\ 05508-270, Sao Paulo, SP, Brazil \\ ${ }^{2}$ Center for the Study of Anthropogenic Effects on Marine Resources, Aquatic Mammals \\ Foundation (NEARM/FMA), Av. Tancredo Neves, 5655, Jabotiana, 49095-000, Aracaju, \\ Sergipe, Brazil \\ ${ }^{3}$ Marine Mammals Program, Association for Research and Preservation of Aquatic \\ Ecosystems (PMM/AQUASIS), Av. José de Alencar, 150, Praia de Iparana, SESC Iparana, \\ 61627-010, Caucaia, Ceará, Brazil \\ ${ }^{4}$ Research Group for Amazonian Aquatic Mammals, Mamirauá Institute for Sustainable \\ Development (GPMAA/IDSM), Estr. do Bexiga, 2584, Fonte Boa, 69550-000, Tefé, \\ Amazonas, Brazil
}

\section{ABSTRACT}

The morphology and location of lymph nodes from seven species of Odontocetes, of both sexes and different age groups, were described. All animals were derived from stranding events along the North and Northeastern coasts of Brazil. After the identification of lymph nodes in situ, tissue samples were analyzed for light and electron microscopy. Vascular volume density (VVD) and vascular length density (VLD) were evaluated in the mesenteric lymph nodes. Lymph nodes occurred as solitary nodules or in groups, varying in shape and size. In addition to using the nomenclature recommended by Nomina Anatomica Veterinaria, new nomenclatures were suggested based on the lymph nodes topography. Lymph nodes were covered by a highly vascularized and innervated capsule of dense connective tissue, below which muscle fibers were observed, inconsistently, in all studied species. There was no difference in VLD among different age groups. However, VVD was higher in adults. Lymph nodes parenchyma was divided into an outer cortex, containing lymph nodules and germinal centers; a paracortical region, transition zone with dense lymphoid tissue; and an inner medulla, composed of small irregular cords of lymphatic tissue, blood vessels, and diffuse lymphoid tissue. Abundant collagen fibers were observed around arteries and arterioles. Germinal centers were more evident and developed in calves and young animals, being more discrete and sparse in adults. The morphology of lymph nodes in Odontocetes was typical of that observed in other terrestrial mammals. However, new groups of lymph nodes were described for seven species occurring in the Brazilian coast. Anat Rec, 297:939-948, 2014. (c) 2014 Wiley Periodicals, Inc.

Key words: lymphoid system; Cetacea; anatomy; microscopy; immune system

Grant sponsor: Sao Paulo Research Foundation (FAPESP); Grant number: 2012/01964-0.

*Correspondence to: Fernanda M. O. Silva, Department of Surgery, School of Veterinary Medicine and Animal Science, University of São Paulo, Av. Prof. Dr. Orlando Marques de Paiva, 87, Cidade Universitária, 05508-270, Sao Paulo, SP, Brazil. E-mail: fernanda_fmos@hotmail.com
Received 22 October 2013; Accepted 16 December 2013. DOI 10.1002/ar.22871

Published online 22 January 2014 in Wiley Online Library (wileyonlinelibrary.com). 
Anexo D - Artigo sobre a morfologia do baço

Zoomorphology (2014) 133:343-350

DOI $10.1007 / 500435-014-0223-x$

ORIGINAL PAPER

\section{Accessory spleen in cetaceans and its relevance as a secondary lymphoid organ}

Fernanda Menezes de Oliveira e Silva • Vitor Luz Carvalho • Juliana Plácido Guimarães • Jociery Einhardt Vergara-Parente $\cdot$ Ana Carolina Oliveira de Meirelles ·

Miriam Marmontel · Maria Angelica Miglino

Received: 7 January 2014/Revised: 13 February 2014/Accepted: 19 February 2014/Published online: 15 March 2014

(c) Springer-Verlag Berlin Heidelberg 2014

\begin{abstract}
The objective was to determine the prevalence of accessory spleens in cetaceans stranded on the north and northeastern coasts of Brazil and to describe their macroscopic and microscopic characteristics, thereby providing insights into the contribution of these structures to the immune system of cetaceans. Sixty-three Odontocetes and Mysticetes (total of 14 species), male and female, ranging from calves to adults, stranded from 2009 to 2013 on the Brazilian north and northeastern coasts, were evaluated. Accessory spleens were present in 38 animals $(60.3 \%)$, with 1-14 accessory spleens per animal. Their location varied among species, ranging from firmly adherent to the spleen, to the large curvature of the first stomach or both.
\end{abstract}

Communicated by A. Schmidt-Rhaesa

F. M. O. e Silva (四) · J. P. Guimarāes , M. A. Miglino

Departamento de Cirurgia, Faculdade de Medicina Veterinária E Zootecnia, Universidade de São Paulo, Av. Prof. Dr. Orlando

Marques de Paiva, 87. Cidade Universitánia, São Paulo,

SP 05508-270, Brazil

e-mail: femanda_fmos@hotmail.com

F. M. O. e Silva - J. P. Guimaräes - J. E. Vergara-Parente Núcleo de Estudos dos Efeitos Antropogênicos nos Recursos Marinhos, Fundação Mamíferos Aquáticos, Av. Tancredo Neves, 5655, Jabotiana, Aracaju, SE 49095-000, Brazil

V. L. Carvalho - A. C. O. de Meirelles

Programa de Mamíferos Marinhos, Associação de Pesquisa e Preservação de Ecossistemas Aquáticos, Av. José de Alencar, 150, Praia de Iparana, SESC Iparana, Caucaia, CE 61627-010, Brazil

M. Marmontel

Grupo de Pesquisa em Mamíferos Aquáticos Amazônicos, Instituto de Desenvolvimento Sustentável Mamirauá, Estr. do Bexiga 2584, Fonte Boa, Tefé, AM 69550-000, Brazil
The presence of these structures was apparently not related to age or sex. However, there was a higher prevalence in animals with a greater body size and known to make deeper dives. Both primary and accessory spleens had similar macroscopic morphology with no demarcation between cortex and medulla. Both primary and accessory spleens had similar histological characteristics. Furthermore, it was noteworthy that germinal centers became more discrete and reduced in number with increasing age. In conclusion, we inferred that accessory spleens may be an additional mechanism for adaptation to diving and that they have a complementary reservoir function and thus can be considered compensatory lymphoid organs to splenic activity.

Keywords Spleen - Cetacea - Lymphoid system . Immune system 